\title{
Amphiregulin Mediates Estrogen, Progesterone, and EGFR Signaling in the Normal Rat Mammary Gland and in Hormone-Dependent Rat Mammary Cancers
}

\author{
Anastasia Kariagina • Jianwei Xie • \\ Jeffrey R. Leipprandt • Sandra Z. Haslam
}

Published online: 23 November 2010

(C) The Author(s) 2010. This article is published with open access at Springerlink.com.

\begin{abstract}
Both estrogen (E) and progesterone (P) are implicated in the etiology of human breast cancer. Defining their mechanisms of action, particularly in vivo, is relevant to the prevention and therapy of breast cancer. We investigated the molecular and cellular mechanisms of $\mathrm{E}$ and/or P-induced in vivo proliferation, in the normal rat mammary gland and in hormone-dependent rat mammary cancers which share many characteristics with the normal human breast and hormone-dependent breast cancers. We show that $\mathrm{E}+\mathrm{P}$ treatment induced significantly greater proliferation in both the normal gland and mammary cancers compared to $\mathrm{E}$ alone. In both the normal gland and tumors, E+P-induced proliferation was mediated through the increased production of amphiregulin (Areg), an epidermal growth factor receptor (EGFR) ligand, and the activation of intracellular signaling pathways (Erk, Akt, JNK) downstream of EGFR that regulate proliferation. In vitro experiments using rat primary mammary organoids or T47D breast cancer cells confirmed that Areg and the synthetic progestin, R5020, synergize to promote cell proliferation through EGFR signaling. Iressa, an EGFR inhibitor, effectively blocked this proliferation. These results indicate that mediators of cross talk between $\mathrm{E}, \mathrm{P}$, and EGFR pathways may be considered as relevant molecular targets for the therapy of hormone-dependent breast cancers, especially in premenopausal women.
\end{abstract}

Electronic supplementary material The online version of this article (doi:10.1007/s12672-010-0048-0) contains supplementary material, which is available to authorized users.

A. Kariagina $\cdot$ J. Xie $\cdot$ J. R. Leipprandt $\cdot$ S. Z. Haslam $(\square)$

Department of Physiology, Breast Cancer and the Environment

Research Center, Michigan State University,

2201 Biomedical \& Physical Sciences Bldg,

East Lansing, MI, USA

e-mail: shaslam@msu.edu
Keywords Progesterone - Estradiol · Progesterone receptor $\cdot$ Amphiregulin · EGFR · Mammary gland . Proliferation $\cdot$ Mammary cancer

\section{Introduction}

Estrogen (E) and progesterone $(\mathrm{P})$ are implicated in the etiology of breast cancer [1, 2]. However, their precise cellular and molecular mechanisms of action in the breast, particularly in vivo, are not well understood. Determining how $\mathrm{E}$ and/or P contribute to proliferation is important for understanding their roles in the normal breast and in the etiology of breast cancer. While the role of $\mathrm{E}$ in breast cancer has been widely studied, less is known about the role of P. This is particularly relevant because, in postmenopausal women, hormonal therapy with estrogen plus progestin (compared to estrogen alone) significantly increases breast cancer risk [2].

$\mathrm{P}$ imparts its biological action via two major progesterone receptor (PR) isoforms, PRA and PRB. Numerous lines of evidence suggest that PRA and PRB have distinct physiological functions in vitro and in vivo. Experiments using stable monoclonal cell lines of T47D human breast cancer cells that are PR negative, express only PRA, or express only $\mathrm{PRB}$, have shown that PR isoforms differ in their ability to activate gene transcription, to interact with cytoplasmic signaling cascades, and in their requirements for activation by ligand [3-5]. Studies in mice lacking or overexpressing PR isoforms in the mammary gland indicate that PRA may be involved in sidebranching, while PRB is critical for lobuloalveolar formation during pregnancy [6-8].

Studies in the T47D breast cancer cell line have demonstrated that $\mathrm{P}$ action is closely interconnected with epidermal growth factor receptor (EGFR) signaling [9-11]. 
PRB seems to be a critical mediator of the cross talk between P and EGFR pathways. P action via PRB but not PRA leads to an autocrine activation of EGFR that results in sustained phosphorylation of Erk [11]. In turn, epidermal growth factor (EGF) treatment activates several intracellular signaling pathways downstream of EGFR that dramatically increase transcriptional activity of PRB both in the presence and absence of ligand $[12,13]$. It is currently not known whether the cross talk between P and EGFR signaling takes place in the normal breast and primary mammary cancers in vivo.

Recent studies of PR isoform expression in the normal human breast have shown that the developmental pattern of PR isoform expression, PR isoform colocalization, and celltype specific expression of PR isoforms are similar to those observed in the rat mammary gland [14]. Both the human breast and rat mammary gland have a similar ductal-lobular organization $[15,16]$, and mammary cancers induced in the rat are predominantly hormone-dependent similar to the majority of human breast cancers. Therefore, studies on the mechanisms of $\mathrm{P}$ action in the normal rat mammary gland and hormone-dependent rat mammary cancers may provide insights into $\mathrm{P}$ action that are relevant to the human breast and breast cancer.

We report that $\mathrm{E}$ and $\mathrm{P}$ work together in vivo in cells coexpressing estrogen receptor $\alpha(\mathrm{ER} \alpha)$, PRA, and PRB to induce robust proliferation in both the normal mammary gland and hormone-dependent mammary cancers through the induction of amphiregulin (Areg). We propose that Areg acts as an autocrine/paracrine EGFR ligand to activate EGFR downstream signaling that, in concert with $\mathrm{P}$ acting through $\mathrm{PRB}$, promotes proliferation in $\mathrm{ER} \alpha+\mathrm{PRA}+\mathrm{PRB}+$ and ER $\alpha-P R A-P R B+$ cells. Furthermore, in vitro experiments showed that Iressa, an EGFR inhibitor, can effectively block this pathway and proliferation. The conserved cross talk between E, P, and EGFR signaling in mammary tumors suggests that combining EGFR inhibitors with antiestrogen therapy may prove beneficial in the treatment of hormone-dependent human breast cancers, in particular, in premenopausal women.

\section{Methods}

Animals

Normal Mammary Gland Adult 18-week-old SpragueDawley rats (Charles-River Laboratory, Raleigh, NC, USA) were ovariectomized (OVX), and 2 weeks later, the animals were injected subcutaneously with vehicle control, E $(17 \mu \mathrm{g} / \mathrm{kg}), \mathrm{P}(15 \mathrm{mg} / \mathrm{kg})$, or a combination of $\mathrm{E}+\mathrm{P}$ $(17 \mu \mathrm{g} / \mathrm{kg}+15 \mathrm{mg} / \mathrm{kg}$ ) daily for 3 days. Sham-operated, vehicle-treated rats served as ovary-intact control (OI). For
Elvax pellet implant experiments, ovariectomized animals were implanted in the right inguinal mammary gland with an Elvax 40P (DuPont Inc.) pellet containing human recombinant Areg (Sigma, St. Louis, MO, USA) $(10 \mu \mathrm{g}$ Areg $+0.2 \mathrm{mg}$ bovine serum albumin (BSA)/pellet); the contralateral inguinal gland was implanted with a control pellet containing only BSA $(0.2 \mathrm{mg})$ as previously described [17]. Control, E, or P injections daily for 3 days were initiated immediately after pellet implantation.

Mammary Cancer For mammary cancer development, ovariectomized 50-day-old rats were implanted with silastic pellets containing E $(2.5 \mathrm{mg} / 1 \mathrm{~cm})$ with or without four pellets releasing P $(50 \mathrm{mg} / 4 \mathrm{~cm})$ and treated with a single intragastric dose $(50 \mathrm{mg} / \mathrm{kg})$ of 7,12-dimethylbenz $[\alpha]$ anthracene. Normal mammary tissues and tumors were fixed in $10 \%$ buffered formalin and paraffin-embedded for immunohistochemical analysis or flash-frozen in liquid nitrogen and stored at $-80^{\circ} \mathrm{C}$ for messenger RNA (mRNA) or protein analysis. For all experiments, animals were euthanized $2 \mathrm{~h}$ after i.p. injection with 5-bromo-2deoxyuridine (BrdU) (Sigma) $(70 \mathrm{mg} / \mathrm{kg}$ ). All animal handling procedures were approved by the Michigan State University Committee on Animal Use and Care.

Cell Lines T47D cell lines, T47D-Y (lacking PR), T47DYA (expressing only PRA), and T47D-YB (expressing only PRB) [18], were generously provided by Dr. KB Horwitz (University of Colorado). Cells were grown in minimal essential media and $5 \%$ fetal bovine serum as described [11]. For experiments, cells were cultured in phenol redand serum-free media for $24 \mathrm{~h}$, treated with synthetic progestin R5020 (20 nM) with or without Iressa (gefitinib, ChemieTek, Indianapolis, IN, USA; $500 \mathrm{nM}$ ) or RU486 (mifepristone, Calbiochem, La Jolla, CA, USA; $100 \mathrm{nM}$ ) for $24 \mathrm{~h}$, and then treated with $25 \mathrm{nM}$ Areg for $30 \mathrm{~min}$ according to the published protocol for these cell lines [9].

Analysis of the Cell Cycle in T47D Cells Cells were plated at density $6 \times 10^{5}$ cells/well in six-well plates in the presence of serum. Cells were cultured for $48 \mathrm{~h}$ in serumfree conditions, treated for $24 \mathrm{~h}$, trypsinized, and fixed with $80 \%$ methanol. Cells were stained with 4',6-diamidino-2phenylindole (DAPI) $(1 \mu \mathrm{g} / \mathrm{ml})$ and analyzed with the BD Vantage Turbo SE flow cytometer and ModFit3.2 software.

Primary Culture of the Rat Mammary Organoids in Collagen Gel Primary culture of mammary organoids in collagen gels was performed as described [19]. Organoids were cultured in serum-free media containing $0.1 \%$ BSA and supplemented with $1 \times$ essential amino acids, $0.5 \times$ nonessential amino acids, $0.5 \times$ vitamins (Invitrogen, Carlsbad, CA, USA), $1 \times$ serum replacement 1 reagent, and $0.2 \times$ ITS 
(insulin-transferrin-sodium selenite) media from Sigma for 5 days. Organoids were treated with P (20nM), Areg (25 nM), or Areg+P. Proliferation was assessed by BrdU incorporation for the last $24 \mathrm{~h}$ of culture [19]. Collagen gels were fixed in $10 \%$ buffered formalin, paraffin-embedded, and sectioned for immunohistochemical analysis.

Antibodies The antibodies used in the study were mouse monoclonal anti-human PR antibody (hPRa7), PRAspecific in immunohistochemistry [20], and anti-human PRB (hPRa6), PRB-specific in immunoblot and immunohistochemistry (Neomarkers, CA, USA; dilution 1:100 and1:25, respectively) [20]. Rabbit polyclonal anti-mouse PRB antibody (B15, custom-made by Affinity Bioreagents, Golden, CO, USA; 1:800) was used for immunohistochemistry. The B15 rabbit antibody was developed to specifically detect PRB in the mouse and rat that differs significantly from the human PRB in the B-specific Nterminal region and to reduce the issue of potential for cross-reactivity between two mouse monoclonal antibodies (hPRA6 and hPRA7) that detect human PRA and PRB. The B15 antibody has been shown previously to be specific for the detection of only PRB by immunohistochemistry and immunoblot in rat mammary tissue [21]. Rabbit polyclonal anti-PR antibody (DAKO A0098, Carpinteria, CA, USA) detects both PRA and PRB by immunoblot. Rabbit polyclonal anti- $\alpha$-smooth muscle actin (SMA) $(1: 200)$, mouse monoclonal anti- $\alpha$-tubulin (1:400), anti-cytokeratin 18 (1:100) antibody (Abcam, Cambridge, MA, USA), rabbit polyclonal anti-phospho-Akt1/2/3 (Ser473) (1:75), anti-total Erk (1:200), goat polyclonal anti- $\beta$-actin $(1: 1,000)$ and anti-phospho-c-Jun (Ser73) (1:25), mouse monoclonal anti-c-Fos (1:50), anti-Areg (1:100), antiphospho-Erk (Tyr204) (1:100), rabbit polyclonal antinuclear factor kappa B (NFkB) (p65) (1:50), antibody specific to phospho-serine (1:100) (Santa Cruz Biotechnology, Santa Cruz, CA, USA), rabbit polyclonal anti-cyclin D1 (Biosource, Camarillo, CA, USA; 1:100), rabbit polyclonal anti-EGFR (1:100), mouse monoclonal antiphospho-EGFR (Tyr1068) (1:100) (both from Cell Signaling, Beverly, MA, USA), goat polyclonal anti-Areg (R\&D Systems, Minneapolis, MN, USA; 1:40), rabbit polyclonal anti- $\beta$-catenin, anti-keratin 18 (both from Sigma, St. Louis, MO, USA; 1:200), mouse monoclonal anti-proliferating cell nuclear antigen (PCNA) (Calbiochem, San Diego, CA, USA; 1:100), mouse monoclonal anti-ER $\alpha$ (6F11, Novocastra, UK; 1:10), and sheep polyclonal anti-BrdU antibody (Biodesign International, Saco, ME, USA; 1:25) were used in the experiments. AlexaFluor488, AlexaFluor546, or AlexaFluor633-labeled secondary antibodies against mouse, rabbit, sheep, or goat were purchased from Invitrogen, Eugene, OR, USA. Nuclei were counterstained with DAPI.
Immunohistochemistry Immunoperoxidase staining, single, double, or triple immunofluorescent labeling were performed as described [21] with modification for the triple labeling where the combination of the mouse, rabbit, and goat or mouse, rabbit, and sheep primary antibodies were used. Images were captured with a Nikon inverted epifluorescence microscope or an Olympus Fluoview laser scanning confocal microscope (Mager Scientific, Dexter, MI, USA) and analyzed with MetaMorph software (Molecular Devices Corp., Downington, PA, USA).

Immunoblot and In-cell Western Analysis For immunoblot analysis, samples were homogenized in radioimmunoprecipitation buffer (Santa Cruz Biotechnology) according to the manufacturer's instructions and resolved on $4-20 \%$ NuPAGE gels (Invitrogen). To detect phospho-PRB, $600 \mu \mathrm{g}$ of total protein was immunoprecipitated with a mixture of anti-PR antibodies (DAKO and hPRa7) and blotted onto nitrocellulose membrane. The membrane was incubated with phospho-serine specific antibody (primary mouse $\mathrm{mAb}$ and IRDye ${ }^{\mathrm{TM}} 800$-labeled secondary antibody). This was followed by incubation with PRB-specific antibody (primary rabbit polyclonal B15, 1:500; IRDye ${ }^{\text {TM}} 680$-labeled secondary antibody). Using the LiCor Odyssey detection system allowed simultaneous detection of both antibodies. Colocalization of the two antibodies (anti-phospho-serine and anti-PRB) was used to measure the level of phospho-PRB. Fold change data were obtained by normalization of the band density to the density of $\alpha$-tubulin, $\beta$-actin, keratin 18, or $\operatorname{IgG}$ band (in immunoprecipitation experiments), followed by normalization of obtained values to the value in the control group. For in-cell Western analysis, cells were gown in 96-well plates in triplicates, treated with Areg, R5020 with or without inhibitors as described above, fixed in $10 \%$ buffered formalin, and incubated with primary antibodies for phospho-Akt/tubulin or phospho-Erk/total Erk as described [22]. Anti-mouse or anti-rabbit IRDye ${ }^{\mathrm{TM}} 680$ or IRDye ${ }^{\text {TM}} 800$-labeled secondary antibody was purchased from Li-Cor Biosciences, Lincoln, NE, USA (dilution 1:4,000 for immunoblot; 1:500 for in-cell Western). Membranes and 96-well plates were scanned and analyzed with a Li-Cor Odyssey infrared scanner.

Real-Time RT-PCR Total RNA was isolated using Trizol reagent (Invitrogen) according to the manufacturer's instructions. Preparation of cDNA and real-time PCR analysis were performed as previously described [23]. Expression levels of genes of interest were normalized to $18 \mathrm{~S}$ expression [24]. Primers specific for the rat EGF, epiregulin (Ereg), Epigen, Areg, betacellulin (Btc), TGF $\alpha$, heparin-binding EGF-like growth factor, EGFR, receptor activator of nuclear factor kappa B ligand (RANKL), and 
Wnt4 were purchased from SA Biosciences, Frederick, MD, USA. Delta-Delta CT method was used to calculate changes in gene expression. Tests were performed on RNA isolated from a minimum of three animals or four tumors per experimental group with three technical replicates for each sample. For EGFR ligands, fold change was calculated compared to EGF expression level because it was the lowest expressed EGFR ligand in OVX control (threshold cycle $\sim 29$ ).

Quantitation and Statistical Analysis The number of BrdU+ cells detected by immunoperoxidase staining and the number of PRA, PRB, BrdU, or SMA+ cells, and colocalization of these markers detected by immunofluorescent labeling were quantitated as previously described [21]. In mammary tissue sections, the percent of positive cells was determined for ducts and lobules. The number of positive cells was expressed as the percent of total epithelial cells counted. Results were presented as mean $\pm \mathrm{SEM}$ and differences were considered significant at $P<0.05$ by ANOVA/MANOVA with Duncan's post hoc test where appropriate.

\section{Results}

E and P Synergistically Induce Proliferation in Cells That Express PRB in the Normal Mammary Gland

Cell-type-specific proliferation in normal mammary gland was analyzed by immunohistochemical detection of BrdU incorporation and $\alpha$-SMA, a specific marker of myoepithelial cells (Fig. 1a). Combined 17- $\beta$-estradiol plus progesterone $(\mathrm{E}+\mathrm{P})$ treatment of adult OVX rats produced a robust synergistic increase in the proliferation of epithelial cells (both luminal and myoepithelial cells) in ducts $(\sim 24 \%)$ and lobules $(\sim 39 \%)$. E alone induced significantly less proliferation in ducts $(\sim 4 \%)$ and in lobules $(\sim 3 \%)$, while $\mathrm{P}$ alone did not increase proliferation. The relative effects of $\mathrm{E}$ vs. $\mathrm{E}+\mathrm{P}$ on proliferation were supported by immunoblot detection of a higher level of PCNA protein in E+P-treated glands (Fig. 1b).

Since we observed that both $\mathrm{E}$ and $\mathrm{P}$ were required for robust proliferation, we analyzed the hormonal regulation of PR isoforms and their colocalization with ER $\alpha$ (Fig. 2). PRA expression was E-dependent (Fig. 2a-c); PRApositive cells were virtually undetectable in OVX control (C) or P-treated glands. Treatment with $\mathrm{E}$ or $\mathrm{E}+\mathrm{P}$ restored PRA expression to the level observed in ovary-intact animals. In contrast to PRA, PRB expression was E and P independent (Fig. 2a-d).

Virtually all luminal cells expressing PRA also coexpressed ER $\alpha$ (Fig. 2e) and PRB (Fig. 2a-c). Thus, in OI glands, $98.0 \pm 0.9 \%$ of $\mathrm{ER} \alpha$-positive $(\mathrm{ER} \alpha+)$ cells co- a.

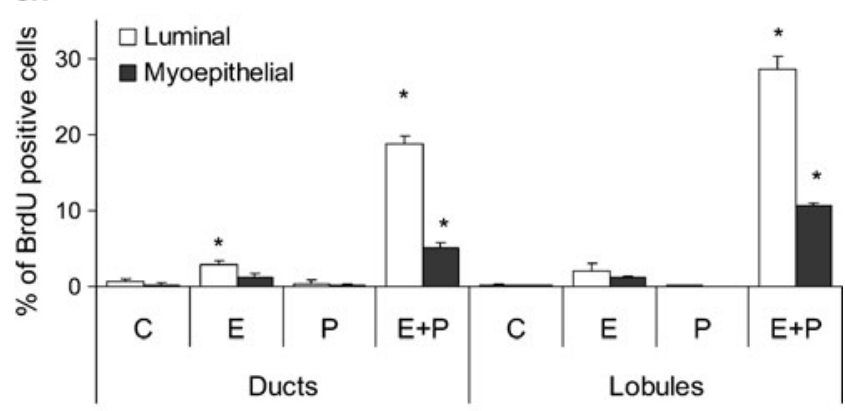

b. $\quad C \quad E \quad P \quad E+P$

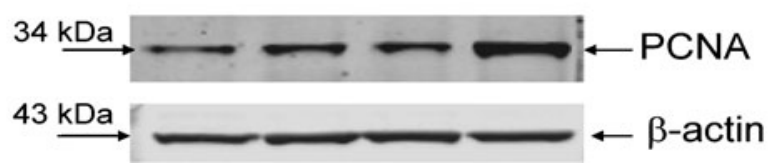

Fig. 1 Hormonal regulation of cell-type-specific proliferation in the normal mammary gland. a Immunofluorescent labeling with antiBrdU and anti-SMA antibody to identify luminal (BrdU positive/SMA negative) and myoepithelial (BrdU positive/SMA positive) proliferating cells in ducts and lobules of OVX animals treated with vehicle (C), E alone (E), $\mathrm{P}$ alone (P), or E+P was performed as described in the "Methods" section. Bars represent mean \pm SEM from three to five animals per experimental group and 1,000 cells counted per animal. $* P<0.05$ compared to control. b Immunoblot analysis of cell cycle regulatory protein PCNA

expressed PRA and $93.9 \pm 1.2 \%$ of PRA + cells coexpressed $E R \alpha$. In contrast, a significant population of $\mathrm{PRB}+$ cells did not co-express PRA (Fig. 2a-c) or ER $\alpha$ (Fig. 2f). Based on these results, we conclude that there are two major populations of steroid receptor-positive luminal cells: cells that co-express ER $\alpha$, PRA, and PRB and cells that express only PRB. As previously reported, myoepithelial cells that expressed only PRB were also detected (data not shown) [21]. However, since ER $\alpha$, PRA, and PRB were colocalized exclusively in luminal cells and luminal cells compose the bulk of hormone-dependent breast cancers, the following experiments have focused on $\mathrm{P}$ effects in the luminal cell compartment.

The majority of proliferating BrdU+ cells expressed only PRB (Fig. 2g). This was especially true for ducts in Etreated glands and for both ducts and lobules in E+P-treated glands. Only a smaller fraction of the proliferating cells coexpressed PRB, PRA, and ER $\alpha$. Receptor-negative (ER $\alpha-1$ $\left.\mathrm{PR}^{-}\right)$proliferating cells were rare in E-treated glands (4\%). In contrast, in E+P-treated glands, there were significantly more proliferating receptor-negative cells.

E and P Regulate Expression of the Paracrine Growth Factor, Amphiregulin

As shown above, most proliferation occurred in cells expressing only PRB (Fig. 2g). Although PRB expression 
a.

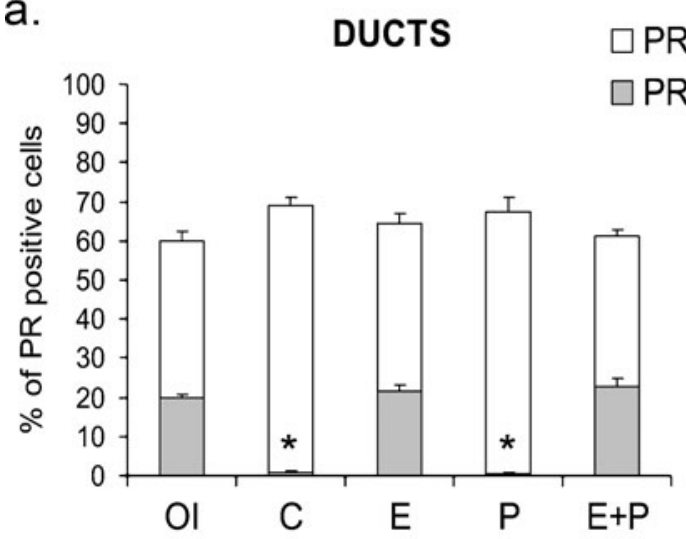

b.

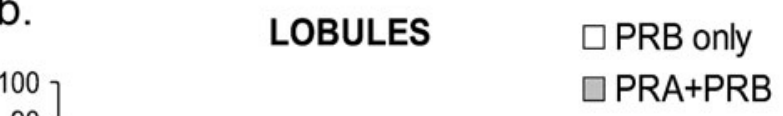

\section{PRA/PRB/DAPI}
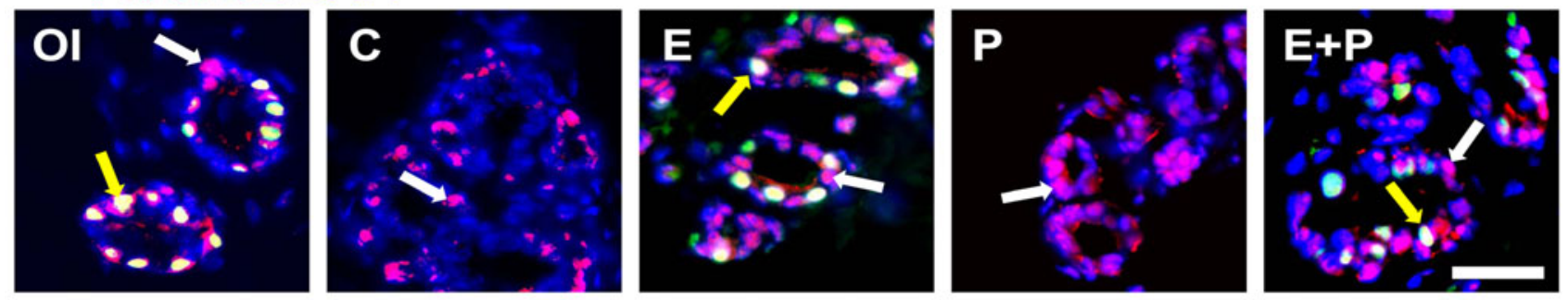

d.

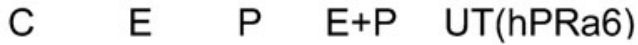

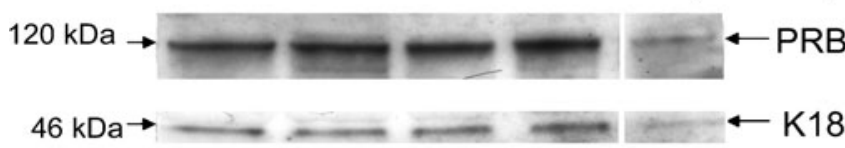

\section{e. ER $\alpha / P R A / D A P I$ f. ER $\alpha / P R B / D A P I$}
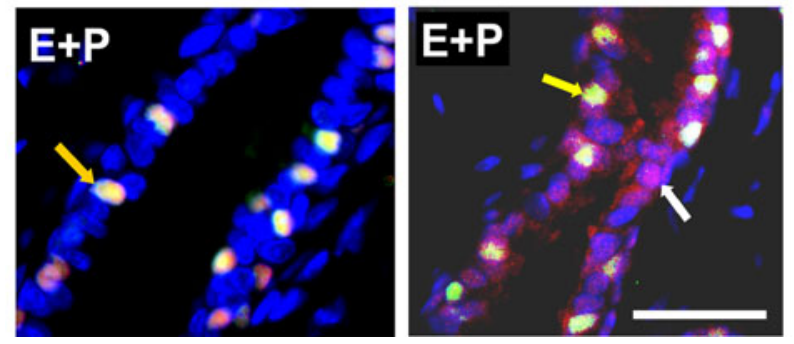

Fig. 2 Hormonal regulation of PR isoform expression and colocalization with $\mathrm{ER} \alpha$ or proliferation. a-c Immunofluorescent labeling with PRA- and PRB-specific antibody. The percentage of PR-positive cells in ducts (a) or lobules (b) from ovary-intact (OI) or OVX animals treated with vehicle (c), E, P, or E $+\mathrm{P}$. Bars represent the mean \pm SEM from three to five animals per experimental group and 1,000 cells counted per animal. $* P<$ 0.05. The percent of PRA+PRB + cells is reduced compared to OI, E- or E+P-treated groups. c Representative merged images of PRA (teal) and PRB (magenta) expression in lobules from OI, C, E, P, or E+P-treated glands. Yellow arrows indicate cells co-expressing PRA and PRB. White arrows indicate cells expressing only PRB. d Immunoblot analysis of

was maintained after OVX (Fig. 2a, b), E and P were both required to induce robust proliferation. This suggested that an E-induced paracrine factor(s) was required in addition to $\mathrm{P}$ for proliferation in cells expressing only PRB. g.

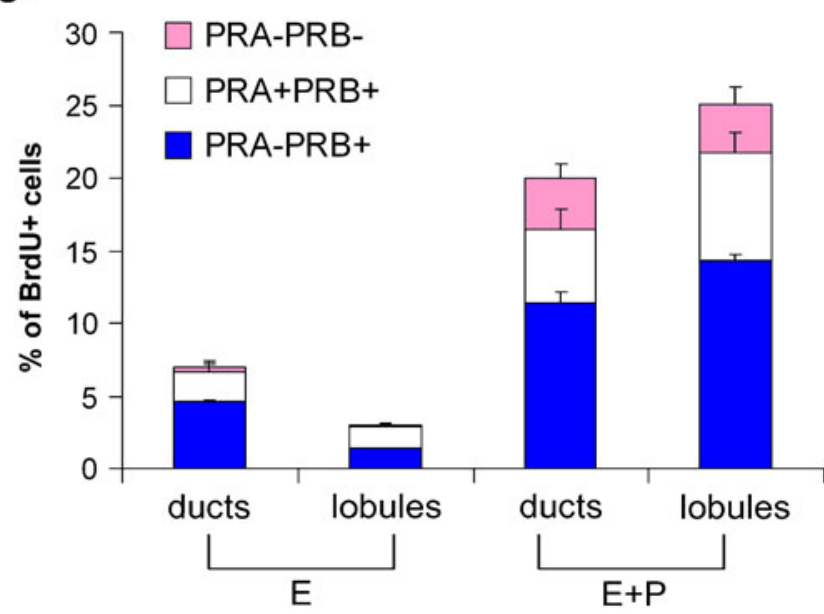

PRB expression in whole mammary gland extracts. Uterine extract (UT) was run as a positive control and was developed with antibody detecting only PRB by immunoblot (hPRa6). e, f Colocalization of ER $\alpha$ with PR isoforms. Representative merged images of immunofluorescent labeling with anti-ER $\alpha$ (green) and e anti-PRA- (magenta) or (f) anti-PRB(magenta) antibodies in E+P-treated ducts. Yellow arrows indicate cells e co-expressing ER $\alpha$ and PRA or $\mathbf{f}$ co-expressing ER $\alpha$ and PRB. White arrows indicate cells expressing only PRB. Nuclei were counterstained with DAPI. Scale bars, $50 \mu \mathrm{m}$. g Triple immunolabeling with PRA-, PRB-, and BrdU-specific antibodies and quantitation of PR+BrdU+ cells. Bars represent the mean \pm SEM from five animals per experimental group

Amphiregulin (Areg), a selective ligand of EGFR, has previously been identified as an E-induced paracrine factor that promotes proliferation of mammary epithelial cells in the mouse [25]. Thus, we considered Areg, as a 
potential E-induced paracrine mediator in the rat. Areg was the most highly induced EGFR ligand by $\mathrm{E}$ or $\mathrm{E}+\mathrm{P}$ treatments (Fig. 3a). Treatment with $\mathrm{E}$ alone or $\mathrm{E}+\mathrm{P}$ increased Areg mRNA $~ 18$-fold, compared to a 5-fold increase by $\mathrm{P}$ alone. Areg protein in whole gland extracts was below the level of detection by immunoblot but could be detected following immunoprecipitation. The level of active Areg protein (43 $\mathrm{kDa}$ form) [26] was significantly increased only in E+P-treated glands (Fig. 3b). The $50-\mathrm{kDa}$ band that represents unprocessed Areg could not be detected because it is masked by prominent IgG bands. Areg protein was localized in cells co-expressing PRA and PRB (these cells also co-express ER (Fig. 2e)), but not in cells that express only PRB (Fig. 3c). In E-treated glands, there were fewer cells expressing Areg than in E+P-treated glands, and Areg expression was negligible in control or P-treated glands.

RANKL and Wnt4 have also been identified as paracrine mediators of P-induced proliferation in the mouse mammary gland [19, 27-29]. Therefore, we measured RANKL and Wnt4 mRNA levels and compared them with Areg mRNA expression (Supplemental Fig. 1). Both RANKL and Wnt4 were increased only in $\mathrm{E}+\mathrm{P}$ and their levels were lower than Areg. Since we observed an induction of both paracrine factors by $\mathrm{E}+\mathrm{P}$ treatment, we analyzed the expression pattern of their respective downstream signaling molecules, NFKB p65 and $\beta$-catenin $[30,31]$, by immunofluorescence. However, we found no noticeable changes in intracellular distribution or intensity of the staining for both NFkB p65 and $\beta$-catenin in $\mathrm{E}+\mathrm{P}$-treated glands compared to OVX control glands (data not shown). Based on these results, further experiments were focused on the role of Areg in mediating $\mathrm{E}+\mathrm{P}$-induced proliferation.

Areg and P Are Sufficient to Induce Proliferation After Ovariectomy In Vivo

To further investigate the potential role of Areg in proliferation, the Elvax pellet mammary implant technique was employed. Rats were OVX and implanted with a pellet releasing a recombinant $11-\mathrm{kDa}$ active fragment of Areg protein; a control pellet was implanted in the contralateral a.

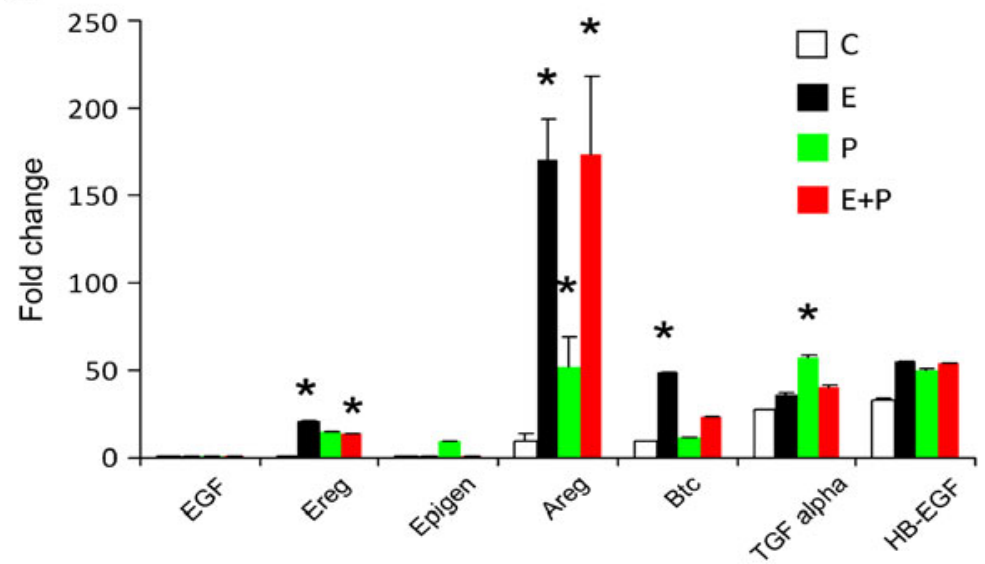

b.

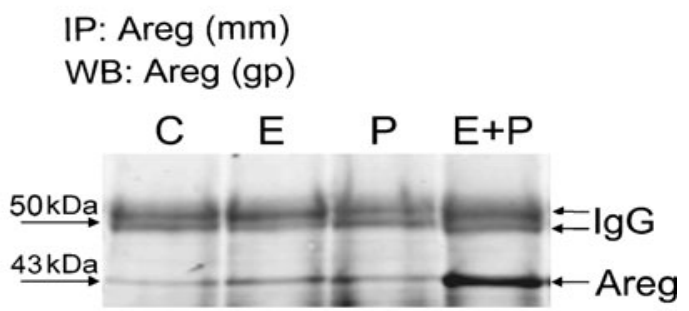

C.

\section{Areg/PRB/PRA}
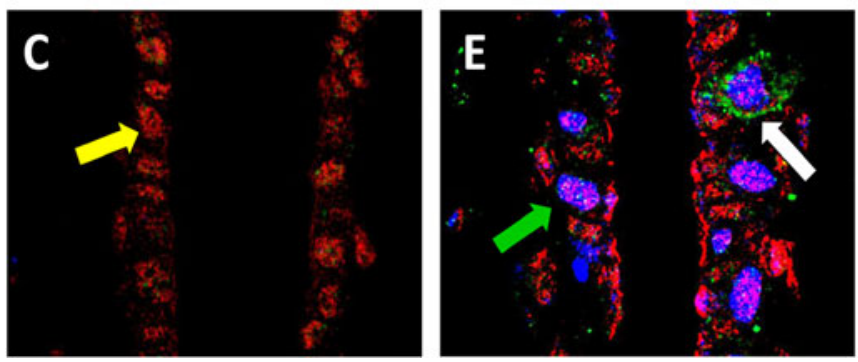

Fig. 3 Hormonal regulation of Areg expression and colocalization with PR isoforms. a Real-time RT-PCR analysis of EGFR ligand mRNA expression. Bars represent the mean \pm SEM fold increase compared to the level of EGF mRNA in OVX control. ${ }^{*} P<0.05$, that hormone treated was greater than control. b Immunoblot analysis of immunoprecipitated Areg protein. $\mathbf{c}$ Immunofluorescent colocalization
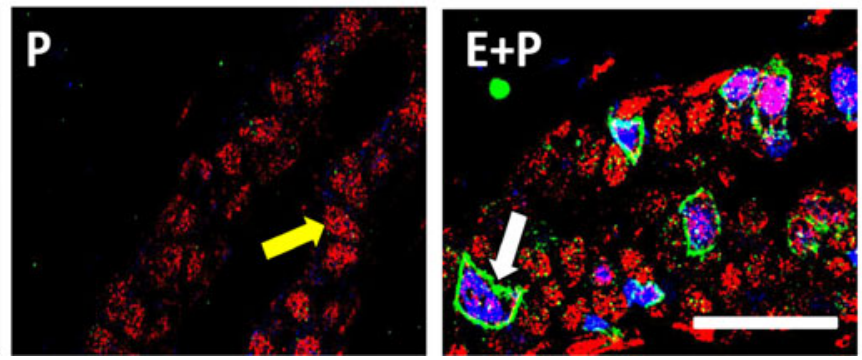

of Areg with PR isoforms. Representative confocal merged images of Areg (green), PRB (red), and PRA (blue) staining in ducts. Yellow arrows indicate cells expressing only PRB (red nuclei). White arrows indicate cells that co-express Areg, PRB, and PRA. Green arrow indicates cells co-expressing PRB and PRA but no Areg. Scale bar, $50 \mu \mathrm{m}$ 
gland of the same animal. These animals were then treated with vehicle control (C), E or P daily for 3 days. Proliferation was analyzed by BrdU incorporation in epithelial cells adjacent to pellet implants (Fig. 4). In Etreated animals, a significant increase in proliferation was observed only in Areg-implanted glands. In P-treated animals, significantly more proliferation was observed in Areg-implanted glands compared to Areg-implanted glands of E-treated animals. Notably, only the Areg implant plus P treatment induced proliferation comparable to that observed with $\mathrm{E}+\mathrm{P}$ treatment. Furthermore, the majority $(98 \pm 2 \%)$ of proliferating cells in both ducts and lobules in Aregimplanted and P-treated glands expressed PRB.

E and P Increase EGFR Expression and Signaling in the Normal Mammary Gland In Vivo

Since hormones regulated the expression of EGFR ligands, we tested whether hormones influenced EGFR expression and EGFR signaling. Indeed, EGFR mRNA (1.2-fold) and protein levels (2-fold) were increased by $\mathrm{E}$ and $\mathrm{E}+\mathrm{P}$ treatment (Fig. 5a). Activation of EGFR by ligand binding leads to activation of several intracellular signaling pathways, such as Akt, JNK, and Erk [9, 32, 33]. Immunoblot analysis showed that $\mathrm{E}+\mathrm{P}$ treatment produced the greatest increase in phospho-Akt levels (Fig. 5b). C-Jun, a nuclear transcription factor and member of activator protein-1 (AP1) complex is activated by JNK phosphorylation. Only E+P increased phospho-c-Jun (Fig. 5b). Consistent with immunoblot results, immunofluorescence analyses showed that phospho-Akt and nuclear phospho-c-Jun staining was increased in epithelial cells by E+P treatment (Fig. 5c, d). Activation of Erk signaling leads to induction of c-Fos, another member of the AP-1 complex. Phospho-Erk levels were increased similarly in E-, P- and E+P-treated glands (Fig. 5b). However, c-Fos levels were increased only in Eand $\mathrm{E}+\mathrm{P}$-treated glands (Fig. 5b). There was no significant difference in the levels of phospho-EGFR among the various treatment groups by immunoblot or immunohistochemistry (data not shown), possibly due to an earlier and transient EGFR phosphorylation.

Studies in T47D breast cancer cells have shown that EGF treatment induces Erk-dependent PRB phosphorylation on serine residues [34]. Phosphorylated PRB is the transcriptionally more active form of the receptor [13]. Consistent with findings in T47D human breast cancer cell line, an analysis of PRB phosphorylation in hormonetreated glands showed 1.9- and 2.4-fold increases in phospho-PRB after $\mathrm{E}$ and $\mathrm{E}+\mathrm{P}$ treatments, respectively (Fig. 5e).
Fig. 4 Effect of Areg implants plus hormone treatments on proliferation. OVX animals were implanted with Elvax pellets containing Areg and BSA control in the contralateral gland and treated with vehicle control (C), E alone, or P alone. a Immunoperoxidase staining with BrdU-specific antibody. Representative images of ducts adjacent to Areg or control implants. Red arrows indicate BrdU+ proliferating epithelial cells. Yellow arrows indicate BrdU+ proliferating stromal cells. Asterisks indicate location of Elvax implant. Scale bar, $100 \mu \mathrm{m}$. b, c Quantitation of proliferating cells in ducts (b) and lobules (c) adjacent to control or Areg implants. Bars represent the mean \pm SEM obtained from 3 to 5 animals per treatment group and a minimum of 500 epithelial cells counted. $* P<0.05$

a.
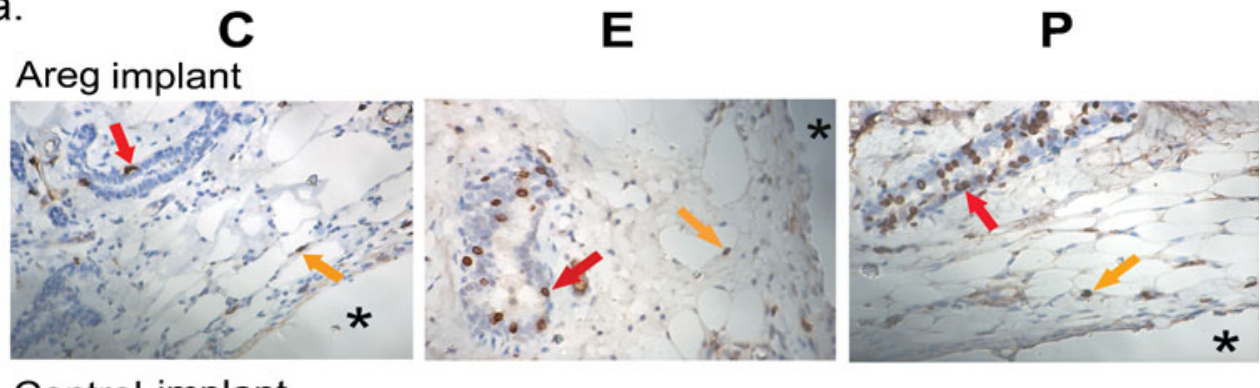

Control implant
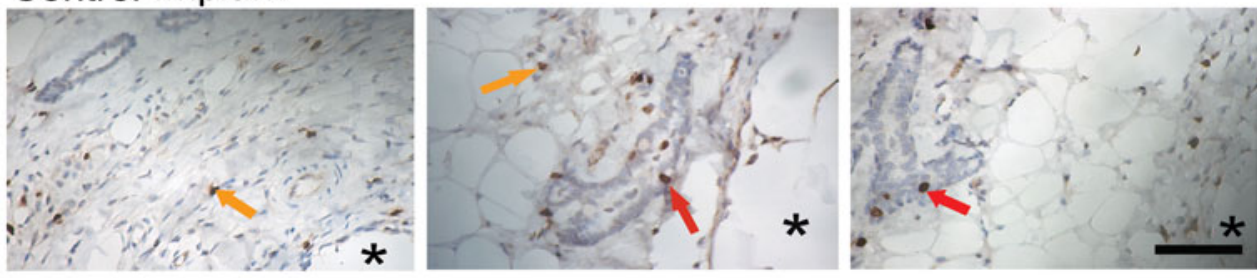

b.

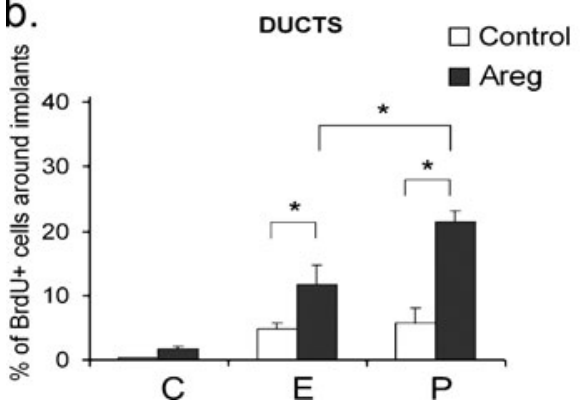

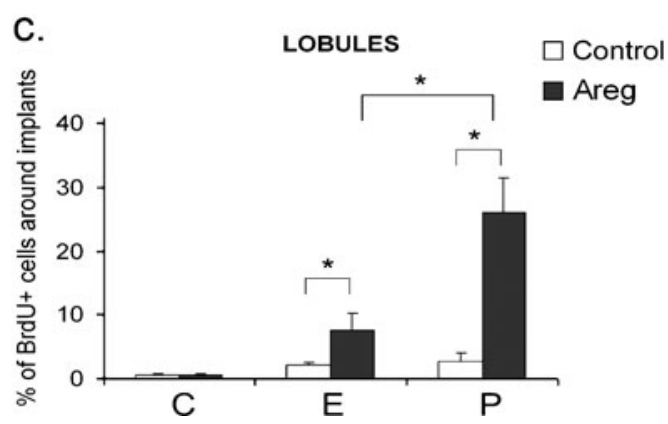


a.

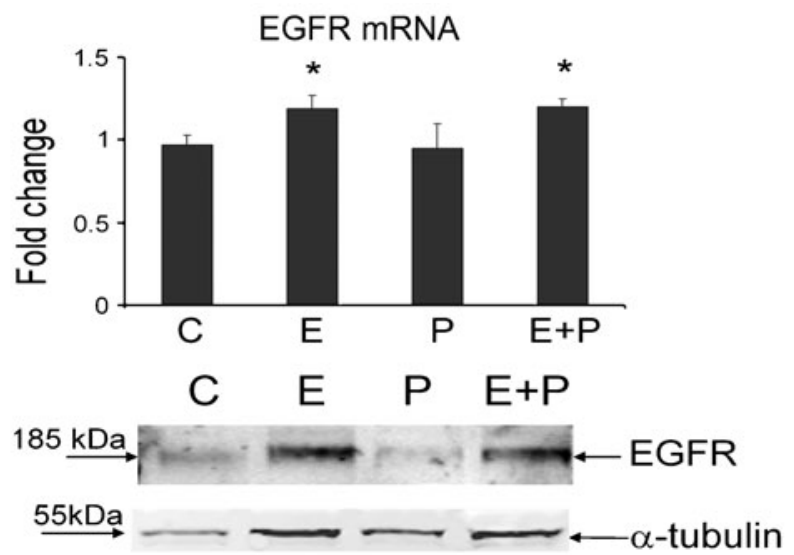

C.
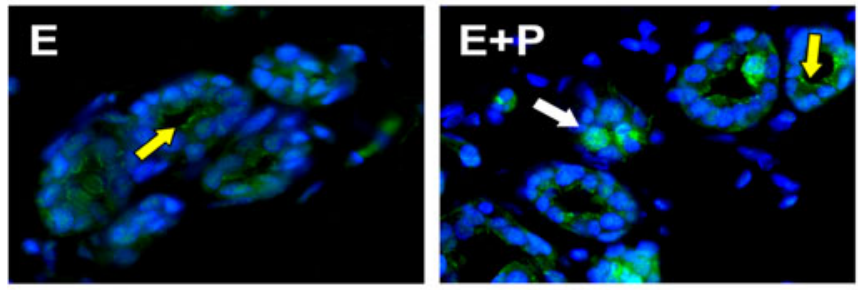

d.

Phospho-C-Jun
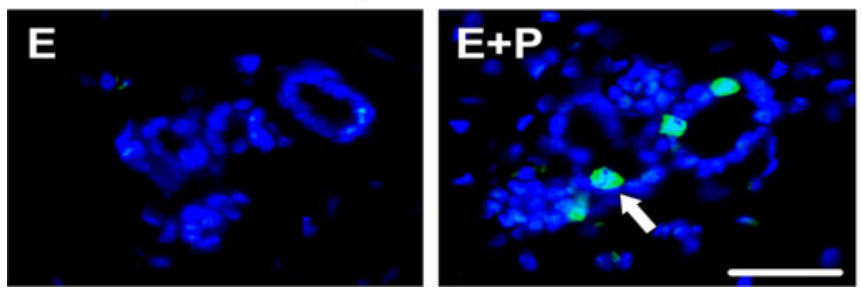

Fig. 5 Hormonal regulation of EGFR signaling. Mammary glands were obtained from OVX animals treated with vehicle (C), with E alone, $\mathrm{P}$ alone, or E+P. a Real-time PCR analysis of EGFR mRNA and immunoblot analysis of EGFR protein expression. Bars represent the mean \pm SEM fold increase. ${ }^{*} P<0.05$ compared to OVX control. $\mathbf{b}$ Immunoblot analysis of phospho-Akt, phospho-c-Jun, phospho-Erk, and c-Fos expression in whole mammary gland extracts. c, d Representative merged images of immunofluorescence analysis of $\mathbf{c}$ phospho-Akt and d phospho-c-Jun in E- or E+P-treated glands. White arrows indicate nuclear localization of phospho-Akt or phospho-cJun. Yellow arrows indicate cytoplasmic phospho-Akt. Nuclei counterstained with DAPI (blue). Scale bar, $50 \mu \mathrm{m}$. e Immunoblot analysis of

P and Areg Cooperate to Induce Proliferation in Primary Rat Mammary Organoids In Vitro

The effects of Areg, $\mathrm{P}$, or Areg $+\mathrm{P}$ on proliferation were also investigated in rat primary mammary organoids cultured in collagen gels in serum-free media. In this culture method, steroid receptor expression is maintained and the three-dimensional architecture and organization of cells is similar to that observed in vivo [19]. Both PRA and PRB were expressed in mammary organoids and PRB was the predominant PR isoform

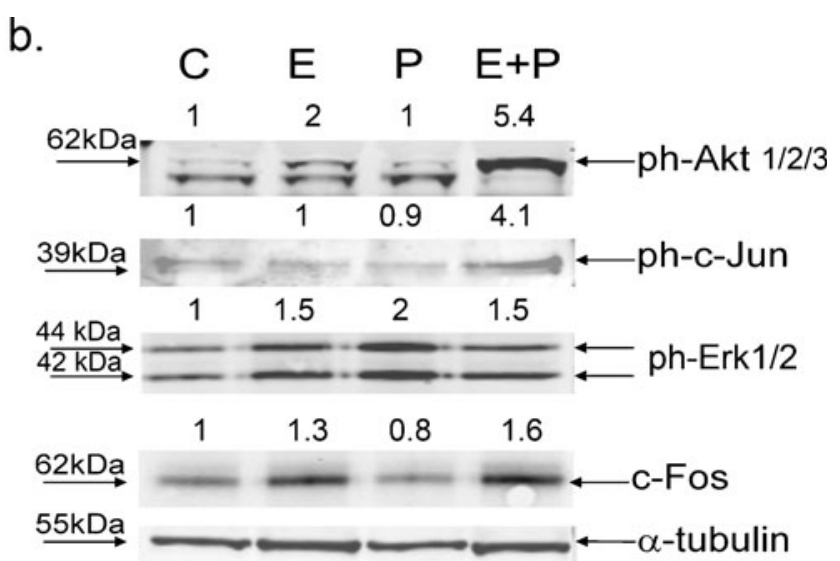

e.

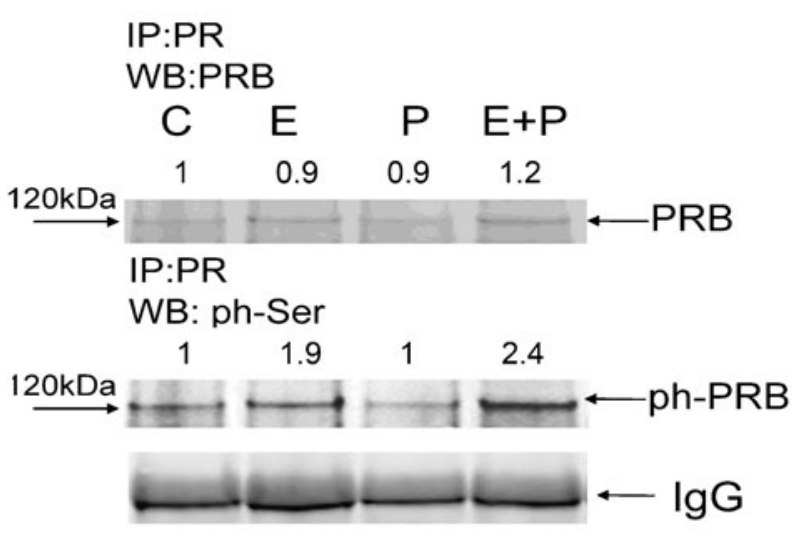

phosphorylated PRB. Total protein was immunoprecipitated with a mixture of anti-PR antibodies (DAKO and hPRa7). Phospho-PRB was detected by immunoblot with phospho-serine-specific antibody (primary mouse $\mathrm{mAb}$ and IRDye ${ }^{\mathrm{TM}} 800$-labeled secondary antibody), followed by incubation with PRB-specific antibody (primary rabbit polyclonalB15, 1:500; IRDye ${ }^{\mathrm{TM}} 680$-labeled secondary antibody). Simultaneous detection and colocalization of the two antibodies (anti-phospho-serine and anti-PRB) was used to measure the level of phospho-PRB. Total PRB and phospho-PRB are shown separately. Numbers above bands indicate fold change compared to OVX control after normalization to $\mathbf{b} \beta$-actin or e IgG

(Fig. 6a), as was observed in the normal mammary gland. A significant increase in proliferation in both luminal and myoepithelial cells was observed only with combined Areg $+\mathrm{P}$ treatment which was decreased by either Iressa or RU486, EGFR, and PR inhibitors, respectively (Fig. 6b). Analysis of PRB expression and colocalization with proliferation showed that $65.8 \pm 6.5 \%$ of BrdU-positive epithelial cells expressed PRB in Areg+P-treated organoids. These results indicate that both EGFR and PR signaling were required for proliferation of mammary organoids. 
a.

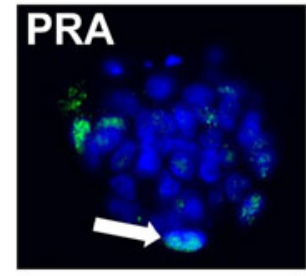

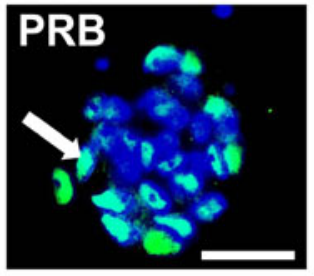

b.

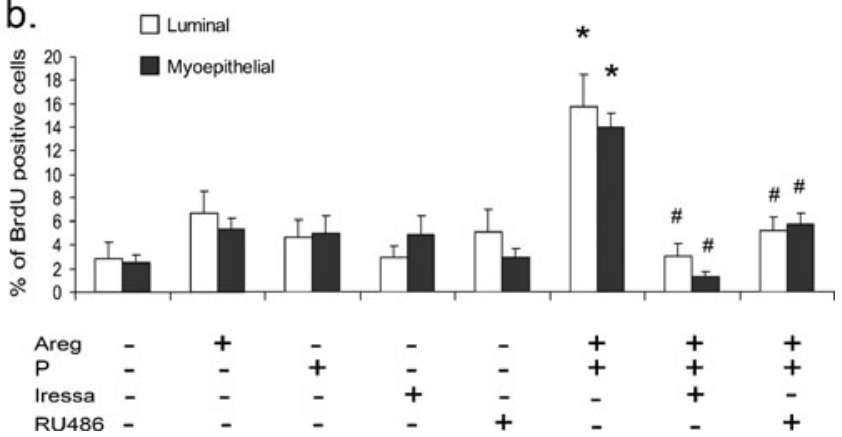

Fig. $6 \mathrm{P}$ and Areg signaling are required for proliferation in primary mammary organoids in vitro. a Merged images of representative PRA and PRB in organoids. Nuclei were counterstained with DAPI (blue). White arrows indicate cells expressing PR. Scale bar, $25 \mu \mathrm{m}$. b Effect of EGFR inhibitor, Iressa, and PR inhibitor, RU486, on proliferation of organoids. Quantitation of proliferating myoepithelial (BrdU

Progestin and Areg Cooperatively Induce Proliferation in T47D Breast Cancer Cells Expressing PRB

The cross talk between $\mathrm{P}$ and EGF signaling in the T47D breast cancer cell line is well documented, and PRB has been shown to mediate the interaction between PR and EGFR signaling [9-11]. We asked whether Areg interacted with $\mathrm{P}$ signaling in a manner similar to EGF in T47D cells. To determine the relative contribution of PR isoforms, T47D cells lacking PR (Y), expressing only PRA (YA), or only PRB (YB) were used. Phosphorylation of Akt and Erk was analyzed by in-cell Western as a measure of EGFR activation (Fig. 7a-d). Akt phosphorylation was slightly increased by Areg or Areg+R5020 only in YB cells (Fig. 7a). Either Iressa or RU486 significantly decreased Areg+R5020-induced phospho-Akt (Fig. 7b). Phospho-Erk was slightly increased in YA cells by R5020 or Areg+ R5020 and dramatically increased with Areg+R5020 in YB cells, which was inhibited by either Iressa or RU486 (Fig. 7c, d). These results indicated that YB cells were the major responders to Areg and R5020 and that Areg and R5020 through binding EGFR or PRB, respectively, cooperated to induce Erk phosphorylation. Consistent with the induction of proliferation only by Areg $+\mathrm{P}$ treatment in mammary organoids, only Areg+R5020 significantly increased in the percentage of YB cells in S phase that was efficiently reduced to basal levels by either Iressa or RU486 (Fig. 7e).

$\mathrm{E}+\mathrm{P}$ Treatment Increases Proliferation

in Hormone-Dependent Rat Mammary Cancers

Mammary tumors (adenocarcinomas) were obtained from carcinogen-treated, OVX rats treated continuously with $\mathrm{E}$ alone or E+P. As previously reported, these tumors are hormone-dependent and express $\mathrm{ER} \alpha$ and PR [35] similar
positive/SMA positive) and luminal (BrdU positive/SMA negative) cells. Bars represent mean \pm SEM; 1,000 epithelial cells counted per treatment. ${ }^{*} P<0.05$, that $A r e g+P$ was greater than all treatment groups. $\# P<0.05$, that Areg $+P$ combined with either Iressa or RU486 treatment was significantly less than Areg+P

to hormone-dependent human breast cancers, the predominant type of human breast cancer. Individual tumors in the $\mathrm{E}$ and $\mathrm{E}+\mathrm{P}$-treated groups varied with respect to proliferation as measured by BrdU incorporation. However, on average, E+P treatment produced significantly greater proliferation than $\mathrm{E}$ alone (Fig. 8a). Consistent with this, the average level of PCNA protein was greater in $\mathrm{E}+\mathrm{P}$ treated tumors compared to E-treated tumors (2.2 \pm 0.3 -fold increase, $P<0.05 ; n=5$ tumors/group) (Fig. 8b). Notably, there was a change in PR isoform expression. Tumors arising in E-treated rats contained significantly more cells expressing only PRA and significantly fewer cells expressing only PRB compared to tumors arising in E+P-treated rats (Fig. 8c). Overall, cells within tumors arising in both $\mathrm{E}$ and E+P-treated rats had greater percentages of cells expressing only PRA and decreased percentages of cells expressing only PRB (Fig. 8c) compared to normal glands of ovary-intact and hormone-treated rats (Fig. 2a, b).

\section{$\mathrm{E}+\mathrm{P}$ Treatment Leads to a Greater Activation of EGFR} Pathway in Mammary Cancers Compared to E Treatment

There was no significant difference in EGFR or Areg mRNA expression in E vs. E+P-treated tumors (Fig. 9a, b). Areg was highly expressed in both $\mathrm{E}$ and $\mathrm{E}+\mathrm{P}$-treated tumors. In contrast to the normal gland, Ereg was also increased in E and E+P-treated tumors (Fig. 9b). Areg protein was expressed in numerous cells in both $\mathrm{E}$ and $\mathrm{E}+\mathrm{P}$-treated tumors in $\mathrm{PRA}+\mathrm{PRB}+$ and in $\mathrm{PRA}+\mathrm{PRB}-$ cells (Fig. 9c). Areg could be detected in tumor extracts without requiring immunoprecipitation. While individual tumors varied with respect to Areg levels (50 and $43 \mathrm{kDa}$ forms), on average there was no significant difference between $\mathrm{E}$ and $\mathrm{E}+\mathrm{P}$-treated tumors ( $n=5-7$ tumors/group) (Fig. 9d). However, E+P treatment led to the increased phosphorylation of Akt and JNK (1.8 \pm 0.3 and $1.4 \pm$ 
a.

Phospo-Akt

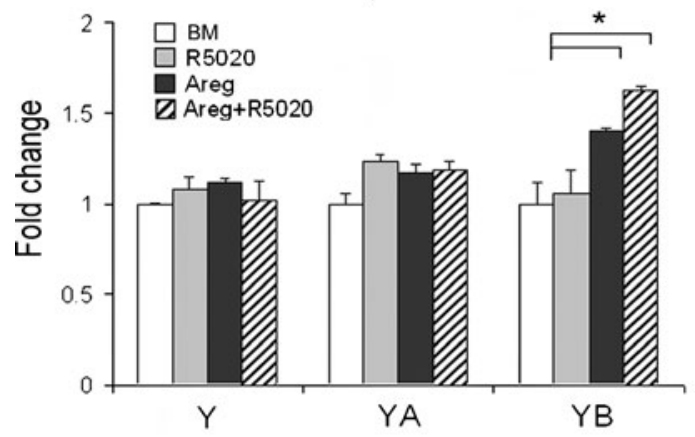

C.

Phospho-Erk

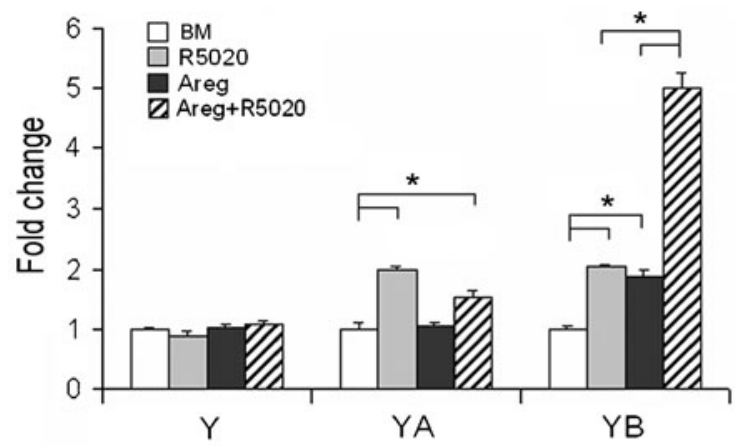

e.

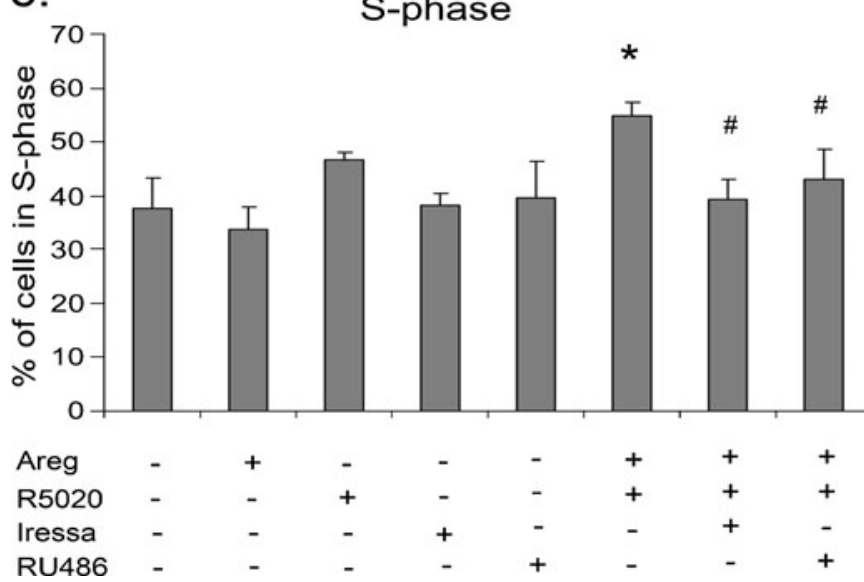

Fig. $7 \mathrm{PR}$ and EGFR signaling and proliferation in T47D breast cancer cells. T47D breast cancer cell lines expressing only PRA (YA), only PRB (YB), or lacking PR (Y) were treated with basal media (BM), R5020, Areg, or Areg+R5020, and analyzed with a phosphoAkt or c phospho-Erk antibody as described in the "Methods" section. The effect of Iressa or RU486 on b Akt or d Erk phosphorylation in

0.1 -fold increases, respectively) $(P<0.05 ; n=3-5$ tumors/ groups), whereas phospho-Erk levels were not significantly different in E- and E+P-treated tumors (Fig. 9d).

We also analyzed expression of RANKL and Wnt4 in hormone-treated mammary tumors (Supplemental Fig. 2). Notably, Areg expression was by far greater than RANKL or Wnt 4 mRNA expression in both E- and E+P-treated tumors.

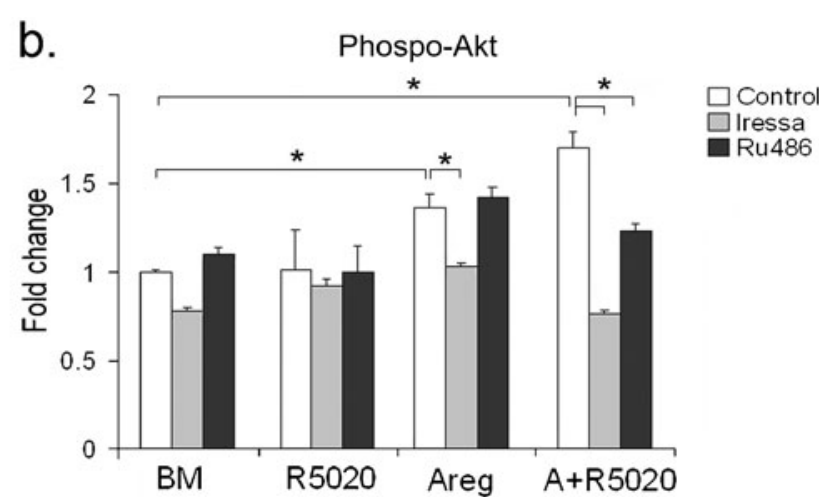

d.

\section{Phospho-Erk}

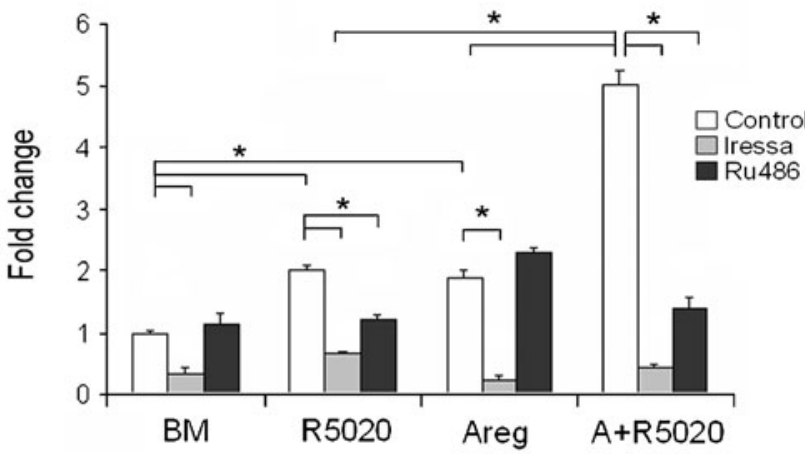

T47D-YB cells. Bars represent the mean \pm SEM from a representative experiment. a-d $* P<0.05$ for comparisons indicated. e Cell cycle analysis in treated T47D-YB cells. ${ }^{*} P<0.05$, that the percentage of cells in $\mathrm{S}$ phase in Areg+R5020 was greater compared to other treatments. $\# P<0.05$, that Areg+R5020 combined with either Iressa or RU486 treatment was significantly less than Areg+R5020

\section{Discussion}

In the present study, we investigated the molecular and cellular mechanisms underlying $\mathrm{E}$ and/or P-induced proliferation, in the rat normal mammary gland and in hormone-dependent rat mammary cancers. The rat was chosen for these studies because ER $\alpha$, PRA, and PRB exhibit cell-type-specific localization remarkably similar to the adult premenopausal 

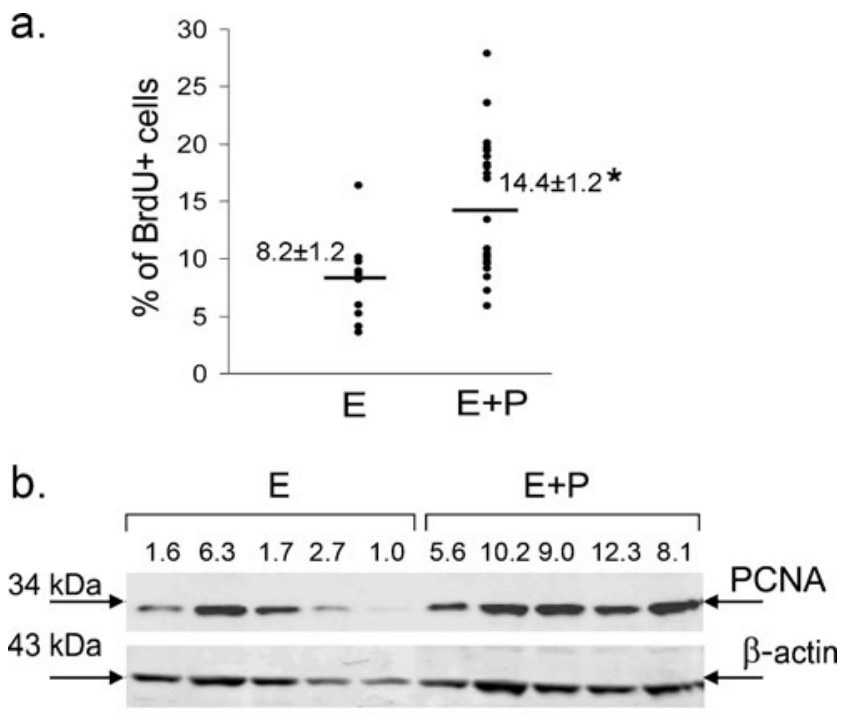

C.

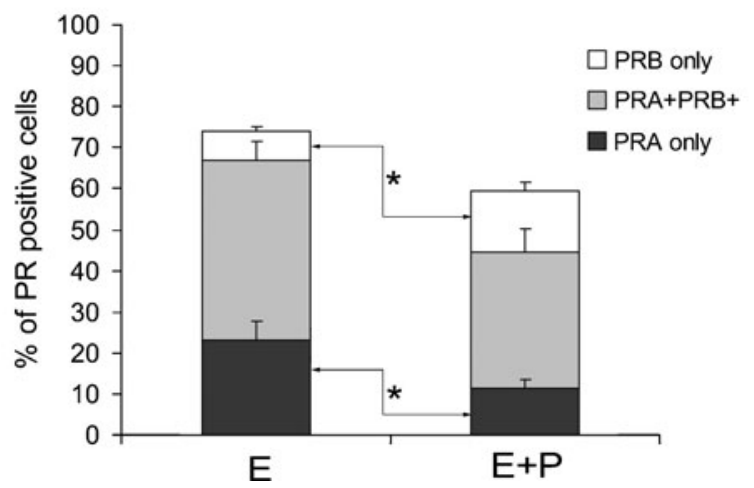

Fig. 8 Hormonal regulation of proliferation and PR isoform expression in hormone-dependent rat mammary tumors. Mammary tumors were obtained from carcinogen-treated OVX animals implanted with $\mathrm{E}$ alone or $\mathrm{E}+\mathrm{P}$. a Tumor cell proliferation was assessed by $\mathrm{BrdU}$ incorporation. Individual tumors ( $n=16-22$ per treatment group) are represented by a single dot. Mean \pm SEM obtained from 1,000 cells counted per tumor. ${ }^{*} P<0.05$. b Immunoblot analysis of PCNA in tumor extracts. Numbers above bands indicate normalized intensity of PCNA band. $\mathbf{c}$ The percentage of PR-positive cells in E or E+P-treated tumors. Bars represent the mean \pm SEM from five tumors per experimental group with 1,000 tumor cells counted. ${ }^{*} P<0.05$ that percent of cells expressing only PRA is increased and cells expressing PRB only is decreased in E-treated tumors

human breast. [14, 36]. Importantly, these studies were carried out in vivo and therefore may provide information relevant to in vivo $\mathrm{P}$ action in the human breast and breast cancer.

Hormonal Regulation of PR Isoform Expression and Proliferation in the Normal Gland

The rat mammary gland contains three populations of luminal epithelial cells: cells that co-express ER $\alpha$, PRA, and PRB; cells that express only PRB; and cells that are ER $\alpha$, PRA, and PRB negative. Cells expressing only PRB are also observed in the normal human premenopausal breast [14] and in the pregnant mouse mammary gland [37]. As reported by others [38], we found that PRA expression was E dependent. In contrast, $\mathrm{PRB}$ expression was $\mathrm{E}$ and $\mathrm{P}$ independent being equally expressed in OVX and hormone-treated glands. This is consistent with the previous observation that only PRB is expressed prior to significant production of ovarian hormones in the pre-pubertal rat mammary gland [21]. In the human breast, an overall reduction of PR expression has been shown after menopause [39] compared to the premenopausal breast [36], presumably due to reduced estrogen levels. However, it is not known whether PRA and PRB are differentially regulated after menopause.

In OVX rats, $\mathrm{E}+\mathrm{P}$ treatment produced significantly greater proliferation than treatment with $\mathrm{E}$ alone. The majority of proliferation occurred in cells expressing only PRB or in cells that were ER $\alpha$, PRA, and PRB negative. Multiple studies in the human breast and rodent mammary glands have reported that proliferation occurs mostly in ER $\alpha /$ PR-negative cells [37, 40, 41]. While our results may seem at odds with these previous reports, it is important to point out that many commercially available anti-PR antibodies detect only PRA and not PRB by immunohistochemistry [20]. Thus, it is quite possible that previous reports failed to detect PRB in proliferating cells. Since a sub-population of cells that express only PRB are also ER $\alpha /$ PRA negative in the rat and human $[14,21]$, the proliferating PRB expressing cells in those studies would have been considered to be $\mathrm{ER} \alpha$, PR negative.

Areg, an Autocrine/Paracrine Mediator of P-Induced Proliferation

The requirement of both $\mathrm{E}$ and $\mathrm{P}$ for induction of robust proliferation despite abundant PRB expression after OVX led us to consider that an E-induced paracrine factor in addition to $\mathrm{P}$ was required for proliferation. Based on studies of E-induced Areg, an EGFR ligand in mouse mammary gland [25] and $\mathrm{P}$ action in T47D breast cancer cells, as well as the interaction of PR and EGFR, we investigated EGFR ligands as potential candidates of the Einduced paracrine factor. Within the 3-day time frame of hormone treatments herein, Areg was by far the most highly E-induced EGFR ligand in the rat mammary gland. The human Areg gene has a putative estrogen response element [42] and Areg expression is strongly induced by $\mathrm{E}$ in the human breast [43]. Thus, E-induced Areg expression in the rat is consistent with findings in the human and mouse mammary glands. In the rat, despite the increased Areg mRNA levels induced by E, the highest level of Areg protein was observed only in E+P-treated glands and was detected in cells expressing ER $\alpha$, PRA and PRB, but not in cells expressing only PRB. Differential regulation of Areg mRNA and protein has been previously observed in human 


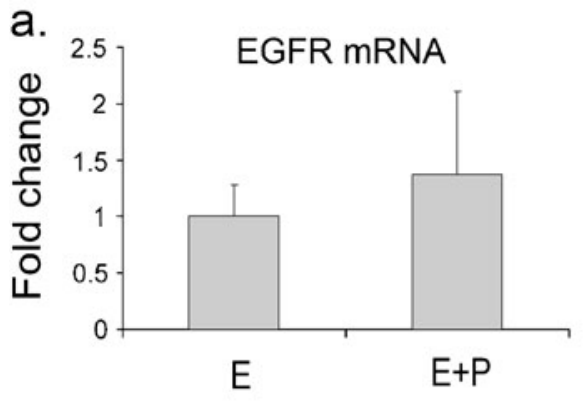

C.

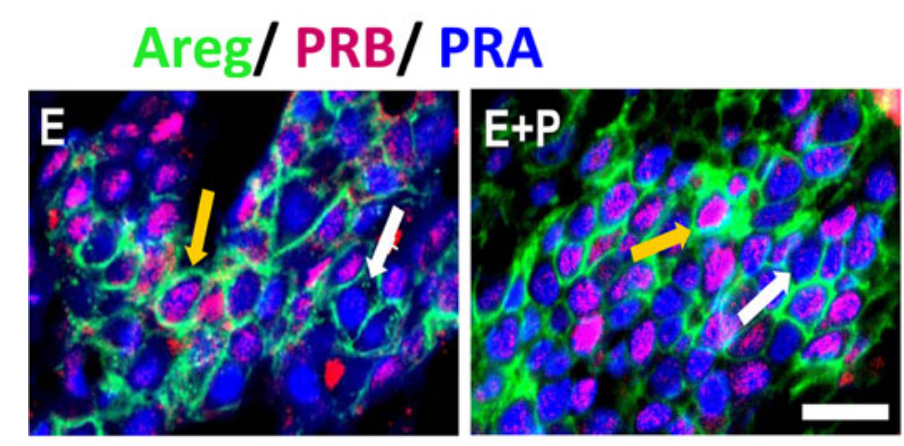

b.

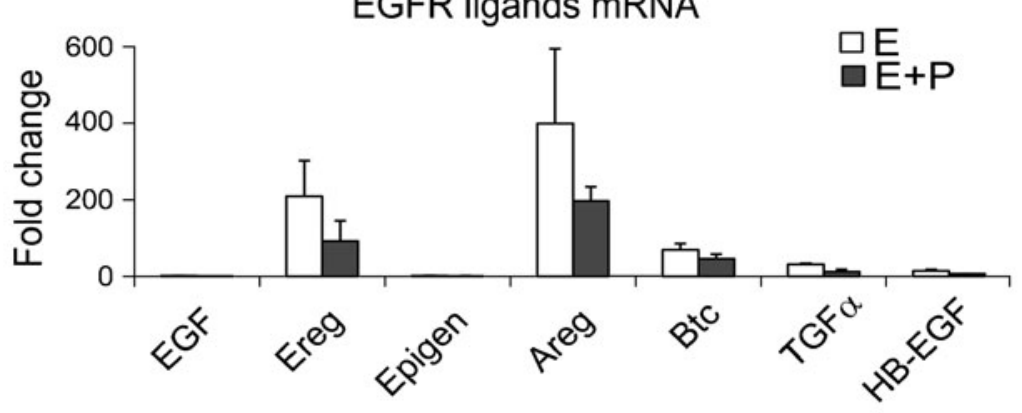

d.
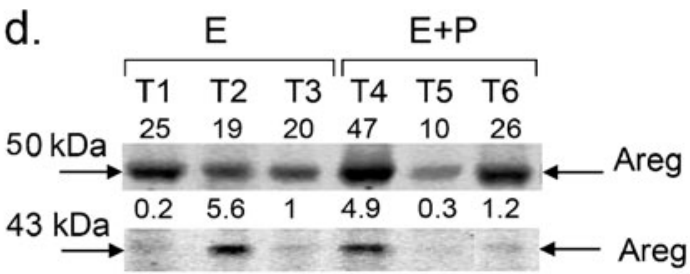

$65 \mathrm{kDa} \quad \begin{array}{llllll}1.0 & 1.4 & 1.4 & 8.8 & 4.7 & 1.9\end{array}$

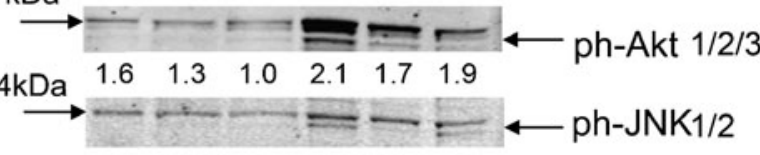

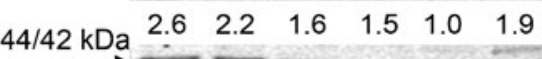

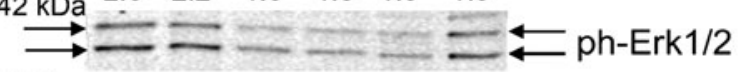

$45 \mathrm{kDa}$

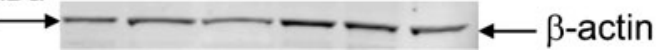

indicate cells co-expressing Areg and PRA. Yellow arrows indicate cells co-expressing Areg, PRB, and PRA. Scale bar, $75 \mu \mathrm{m}$. d Immunoblot analysis of Areg, phospho-Akt, phospho-JNK, and phospho-Erk for the same E- or E+P-treated tumors. Numbers above bands indicate relative band intensity normalized to $\beta$-actin

targets, NFkB p65 and $\beta$-catenin, was not altered by E+P treatment. Thus, compared to Areg, it appears that under the current experimental conditions (OVX followed by 3 days of hormone treatment), RANKL and Wnt4 have a lesser effect on proliferation.

Interactions Between P, E, and EGFR Signaling

The E-dependent upregulation of EGFR protein expression that was observed in the normal gland likely enhances responsiveness to Areg. Areg binding to EGFR can activate Akt, JNK, and Erk [9, 33, 45]. We found that E+P treatment of the normal gland markedly activated not only Akt, a key regulator of cell proliferation and survival [46], but also c-Jun, a molecular target of JNK. Importantly, both phospho-Akt and phospho-c-Jun were detected in luminal epithelial cells, consistent with EGFR signaling occurring in the mammary epithelium.

Activation of JNK and Erk leads to formation of an activated AP-1 transcription complex (phospho-c-Jun/c-Fos 
heterodimer) important for cell proliferation [47]. While cFos was equally increased by $\mathrm{E}$ or $\mathrm{E}+\mathrm{P}$ treatment, phosphoc-Jun was increased only by $\mathrm{E}+\mathrm{P}$, suggesting that both $\mathrm{E}$ and $\mathrm{P}$ were required for activation of $\mathrm{AP}-1$. In the mouse, the blockade of AP-1 function results in decreased proliferation, stunted mammary gland growth, and reduced sidebranching, suggesting a pivotal role for AP-1 in epithelial proliferation [48]. E+P treatment also increased PCNA protein, a promoter of cell cycle progression. Interestingly, PCNA has been identified as a PRBdependent gene in T47D breast cancer cells [49]. We speculate that in the rat mammary gland PCNA transcription is also driven by liganded PRB.

Extensive cross talk between EGF and P signaling has been shown in T47D breast cancer cells $[9,10,50]$. EGF induces a transient phosphorylation of Ser294 in PRB in an Erkdependent manner [10]. This phosphorylation causes nuclear translocation of un-liganded PRB and renders PRB more sensitive to ligand [10]. In this study, we found that PRB phosphorylation of serine residues was increased in vivo by $\mathrm{E}$ and further increased after $\mathrm{E}+\mathrm{P}$ treatment in the normal gland. Thus, the observed phosphorylation of PRB is consistent with Areg production and activation of EGFR signaling in the epithelium and correlates with proliferation of cells expressing PRB. This suggests that phosphorylation of PRB may enhance the transcriptional activity of PRB in vivo.

\section{Interaction Between P and Areg Is Mediated by PRB}

Consistent with published data describing PR and EGFR cross talk [9], we demonstrated in T47D breast cancer cells that $\mathrm{P}$ signaling via PRB, but not PRA, cooperated with Areg signaling. Areg and R5020 acting via PRB synergistically induced Erk phosphorylation and increased proliferation. Inhibitors of EGFR or PR efficiently blocked Erk phosphorylation, providing evidence that both pathways were required for robust Erk phosphorylation. Interestingly, Areg treatment induced only modest Akt phosphorylation in PRB expressing T47D cells that was only slightly increased by the addition of R5020. These data indicate that Erk is the major downstream target of the interaction between EGFR and $\mathrm{P}$ signaling in T47D-YB cells. A diagram summarizing the interactions between $\mathrm{ER} \alpha$, PRA, PRB, and EGFR signaling in the normal rat mammary gland is presented in Fig. 10.

Comparison of E, P, and the EGFR Signaling in the Normal Mammary Gland and Mammary Cancers in the Rat

The combination of $\mathrm{E}+\mathrm{P}$ was more potent than $\mathrm{E}$ alone in promoting proliferation in both normal mammary glands and in mammary tumors that developed in hormone-treated rats. The proliferation rates elicited by $\mathrm{E}$ or $\mathrm{E}+\mathrm{P}$ in tumors

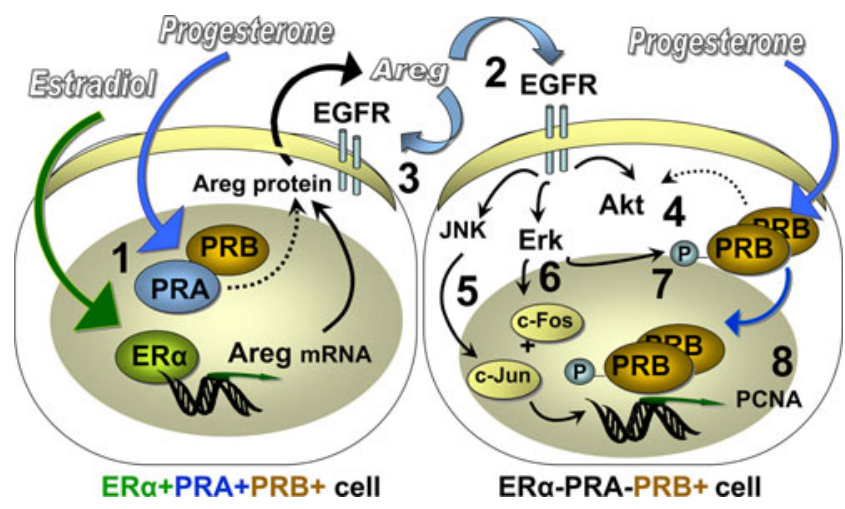

Fig. 10 Diagram of convergence of E, P, and EGFR signaling pathways. $1 \mathrm{E}$ acting via $\mathrm{ER} \alpha$ and $\mathrm{P}$ acting via PRA/PRB induce Areg mRNA expression and protein in ER $\alpha+\mathrm{PRA}+\mathrm{PRB}+$ cells. 2 Secreted Areg acts in a paracrine manner and activates EGFR signaling in ER $\alpha-P R A-$ $\mathrm{PRB}+$ cells and 3 in an autocrine manner in ER $\alpha+\mathrm{PRA}+\mathrm{PRB}+$ cells and activates EGFR signaling. EGFR signaling activates Akt (4), JNK (5), and Erk (6) leading to formation of AP-1 complex (phospho-c-Jun/ c-Fos). 4 PRB may enhance Akt phosphorylation. 7 Activation of Erk leads to phosphorylation of PRB. 8 Activated AP-1 and liganded phospho-PRB induce cell cycle regulatory protein PCNA and proliferation in $\mathrm{ER} \alpha+\mathrm{PRA}+\mathrm{PRB}+$ and $\mathrm{ER} \alpha-\mathrm{PRA}-\mathrm{PRB}+$ cells

were not significantly different from those in normal glands. These results suggest that endogenous $\mathrm{P}$ in premenopausal women and exogenous $\mathrm{P}$ in combined estrogen+progestin hormonal therapy in postmenopausal women may also contribute to tumor proliferation.

The percent of cells co-expressing PRA and PRB was not significantly different between $\mathrm{E}$ and $\mathrm{E}+\mathrm{P}$-treated normal mammary glands. However, tumor development was notably associated with an increased percentage of cells expressing only PRA and a reduced percentage of cells expressing only PRB. Thus, altered PR isoform expression in tumors may lead to the increased $\mathrm{P}$ signaling via PRA. Predominance of PRA expression has been detected in early precancerous lesions of the human breast suggesting that increased PRA expression is an event associated with the early stages of cancer development [36]. In breast cancers, the predominance of PRA expression is associated with a more aggressive tumor phenotype and worse prognosis for overall survival [51]. Studies in human breast cancer cells have also demonstrated that PRA activates transcription of several genes that are associated with cell transformation and cell motility and may confer a more aggressive cellular phenotype [52]. However, there is another possible mechanism to be considered to explain the observed reduced percentage of PRB positive cells and increased percentage of PRA positive cells in tumors from $\mathrm{E}+\mathrm{P}$-treated rats. This change could be the result of increased PRB phosphorylation and rapid receptor turnover leading to a lack of detection by immunohistochemistry. Rapid turnover of PRB is reported to be related to increased 
transcriptional activity in T47D human breast cancer cells expressing the PRB isoform in the presence of ligand [53]. This could also explain the increased proliferation observed in tumors arising in $\mathrm{E}+\mathrm{P}$-treated rats.

Based on mRNA levels, relative EGFR levels were similar in E- and E+P-treated normal glands and tumors. Analysis of mRNA expression showed that Areg was the most highly expressed EGFR ligand in normal glands and highly expressed in tumors. It should be noted that Ereg levels were similar to Areg levels in tumors and therefore may contribute to proliferation in tumors. In the normal gland, Areg protein was highly induced only in the presence of $\mathrm{E}+\mathrm{P}$. However, in tumors, treatment with either $\mathrm{E}$ alone or $\mathrm{E}+\mathrm{P}$ induced comparable levels of Areg protein. Interestingly, increased Areg protein was not detected in normal mammary cells adjacent to tumors (data not shown). This suggests that increased Areg expression was specifically associated with tumor development and not merely the result of the chronic hormone exposure.

Our results obtained in vivo in the normal rat gland, in rat primary mammary organoid cultures, and in T47D YB cells demonstrated that Areg signaling via EGFR cooperates with $\mathrm{P}$ signaling to promote proliferation. Consistent with this, we also observed a marked activation of signaling pathways downstream of EGFR in E+P-treated normal mammary glands and in E+P-treated tumors compared to treatment with $\mathrm{E}$ alone. However, it should be noted that there was significant variability among tumors in the two treatment groups. These results indicate that the interaction between $\mathrm{P}$ and EGFR signaling that drives proliferation in the normal mammary gland is similarly functional in a subset of tumors. The results in the rat mammary gland and mammary cancer suggest that Akt phosphorylation can serve as an indicator of ongoing $\mathrm{P}$ and EGFR cross talk. In T47D YB cells, Areg+R5020 increased phosphorylation of Erk to a greater extent than Akt. The difference between signaling inT47D cells and signaling in the normal rat mammary gland and tumors may be due to intrinsic species differences in EGFR signaling. It is also possible that dependence on Erk activation may be specific to T47D cells and does not necessarily reflect the features of all human primary hormone-dependent breast cancers. Despite this difference between rat mammary cancers and T47D breast cancer cells, the cross talk between E, P, and EGFR signaling (i.e., Areg production, Akt phosphorylation, Erk phosphorylation) may present important molecular markers and targets for the treatment of hormone-dependent mammary cancers that develop in premenopausal women. In this regard, inhibition of EGFR phosphorylation by Iressa blocked Areg+P-induced proliferation in primary mammary organoids and markedly inhibited Areg+Pinduced Erk phosphorylation that was associated with proliferation in T47D-YB cells. Iressa has been shown to reduce mammary tumor incidence and cause tumor regression in carcinogen-treated rats [54]. Furthermore, the combination of Iressa and an aromatase inhibitor was more effective than Iressa alone [54]. Iressa is currently under investigation in clinical trials for the treatment of breast cancer patients. In a recent trial, Iressa treatment showed a better clinical benefit rate in chemotherapy-naive patients with hormone-dependent breast cancers than in patients with hormone-independent cancers [55]. Our results that demonstrate E, P, and EGFR cross talk in hormonedependent rat mammary cancers provide a plausible explanation for this clinical finding.

Progestins continue to be highly implicated in the etiology of human breast cancer [56]. Recently RANKL, a P-induced paracrine factor, has been implicated in the development of mammary cancer in the mouse $[57,58]$. In the rat (Kariagina and Haslam, unpublished observations) and mouse normal mammary gland [59], RANKL is produced only in cells that express PRA. It should be noted that rat and the mouse mammary glands differ with regard to developmental expression, hormonal regulation, and colocalization of PRA and PRB. In the mouse, PRA and PRB are generally expressed in different cells, PRA expression is significantly maintained after OVX [8], and RANKL can be induced by $\mathrm{P}$ alone [59]. In the rat, virtually no PRA is detectable after OVX, and RANKL induction requires combined $\mathrm{E}+\mathrm{P}$ treatment (Supplemental Fig. 1). In contrast to the mouse, the pattern of PRA and PRB expression and colocalization of both isoforms in the same cell in rat closely resembles the pattern observed in the human breast $[14,21]$. The majority of carcinogeninduced mammary tumors in the rat are $\mathrm{ER}+\mathrm{PR}+$ and hormone dependent in contrast to mouse mammary cancer models which are predominantly ER-PR- and hormone independent. Furthermore, E-treated rats develop mammary cancer in the absence of RANKL expression (Supplemental Fig. 2). This raises the possibility that Areg may be a more relevant E+P-induced mediator of the development of hormone-dependent human breast cancer. While a role of RANKL has not yet been identified in the development of hormone-dependent mammary cancer in the rat, its potential role in tumor cell proliferation and tumor behavior warrants further investigation.

In conclusion, the present study demonstrates that $\mathrm{E}$ and $\mathrm{P}$ interact with EGFR signaling through Areg to induce proliferation in the normal mammary tissue and hormonedependent mammary cancer. Inhibition of EGFR may be a promising therapeutic strategy to be used in combination with anti-hormone therapies for the treatment of hormonedependent breast cancers that exhibit activation of EGFR signaling. This may be particularly relevant for premenopausal women who produce endogenous progesterone. The results obtained herein also indicate that the rat is a relevant 
model for testing therapeutic strategies that can block this signaling pathway.

Acknowledgments The authors thank Jennifer Ward, Kristina Miller, Lyndsi Davenport, Kyle Pohl, Alicia Kramer, Sharmila Kulkarni, Bennett Cho, Howard Herr, and Jang Park for the excellent technical assistance and Dr. Louis King for the analysis of the cell cycle experiments. This work was supported by the U.S. Army Medical Research and Materiel Command under W81XWH-07-10502 (to S.Z.H) and by the Breast Cancer and the Environment Research Centers Grant U01 ES/CA 012800 (to S.Z.H.) from the National Institute of Environment Health Science (NIEHS) and the National Cancer Institute (NCI), National Institutes of Health, Department of Health and Human Services. The contents of the study are solely the responsibility of the authors and do not necessarily represent the official views of the NIEHS or NCI, NIH.

Conflict of interest The authors declare that they have no conflict of interests.

Open Access This article is distributed under the terms of the Creative Commons Attribution Noncommercial License which permits any noncommercial use, distribution, and reproduction in any medium, provided the original author(s) and source are credited.

\section{References}

1. Bernstein L (2002) Epidemiology of endocrine-related risk factors for breast cancer. J Mammary Gland Biol Neoplasia 7:3-15

2. Campagnoli C, Clavel-Chapelon F, Kaaks R, Peris C, Berrino F (2005) Progestins and progesterone in hormone replacement therapy and the risk of breast cancer. J Steroid Biochem Mol Biol 96:95-108

3. Graham JD, Clarke CL (2002) Expression and transcriptional activity of progesterone receptor A and progesterone receptor B in mammalian cells. Breast Cancer Res 4:187-190

4. Tung L, Abdel-Hafiz H, Shen T, Harvell DM, Nitao LK, Richer JK, Sartorius CA, Takimoto GS, Horwitz KB (2006) Progesterone receptors (PR)-B and $-\mathrm{A}$ regulate transcription by different mechanisms: AF-3 exerts regulatory control over coactivator binding to PR-B. Mol Endocrinol 20:2656-2670

5. Boonyaratanakornkit V, McGowan E, Sherman L, Mancini MA, Cheskis BJ, Edwards DP (2007) The role of extranuclear signaling actions of progesterone receptor in mediating progesterone regulation of gene expression and the cell cycle. Mol Endocrinol 21:359-375

6. Mulac-Jericevic B, Mullinax RA, DeMayo FJ, Lydon JP, Conneely OM (2000) Subgroup of reproductive functions of progesterone mediated by progesterone receptor-B isoform. Science 289:1751-1754

7. Shyamala G, Yang X, Silberstein G, Barcellos-Hoff MH, Dale E (1998) Transgenic mice carrying an imbalance in the native ratio of A to B forms of progesterone receptor exhibit developmental abnormalities in mammary glands. Proc Natl Acad Sci USA 95:696-701

8. Aupperlee MD, Haslam SZ (2007) Differential hormonal regulation and function of progesterone receptor isoforms in normal adult mouse mammary gland. Endocrinology 148:2290-2300

9. Lange CA, Richer JK, Shen T, Horwitz KB (1998) Convergence of progesterone and epidermal growth factor signaling in breast cancer. Potentiation of mitogen-activated protein kinase pathways. J Biol Chem 273:31308-31316
10. Daniel AR, Qiu M, Faivre EJ, Ostrander JH, Skildum A, Lange CA (2007) Linkage of progestin and epidermal growth factor signaling: phosphorylation of progesterone receptors mediates transcriptional hypersensitivity and increased ligand-independent breast cancer cell growth. Steroids 72:188-201

11. Faivre EJ, Lange CA (2007) Progesterone receptors upregulate Wnt-1 to induce epidermal growth factor receptor transactivation and $\mathrm{c}$-Src-dependent sustained activation of Erk1/2 mitogenactivated protein kinase in breast cancer cells. Mol Cell Biol 27:466-480

12. Pierson-Mullany LK, Lange CA (2004) Phosphorylation of progesterone receptor serine 400 mediates ligand-independent transcriptional activity in response to activation of cyclindependent protein kinase 2. Mol Cell Biol 24:10542-10557

13. Faivre EJ, Daniel AR, Hillard CJ, Lange CA (2008) Progesterone receptor rapid signaling mediates serine 345 phosphorylation and tethering to specificity protein 1 transcription factors. Mol Endocrinol 22:823-837

14. Taylor D, Pearce CL, Hovanessian-Larsen L, Downey S, Spicer DV, Bartow S, Pike MC, Wu AH, Hawes D (2009) Progesterone and estrogen receptors in pregnant and premenopausal non-pregnant normal human breast. Breast Cancer Res Treat 118:161-168

15. Russo J, Gusterson BA, Rogers AE, Russo IH, Wellings SR, van Zwieten MJ (1990) Comparative study of human and rat mammary tumorigenesis. Lab Invest 62:244-278

16. Russo J, Russo IH (1996) Experimentally induced mammary tumors in rats. Breast Cancer Res Treat 39:7-20

17. Silberstein GB, Van Horn K, Shyamala G, Daniel CW (1994) Essential role of endogenous estrogen in directly stimulating mammary growth demonstrated by implants containing pure antiestrogens. Endocrinology 134:84-90

18. Sartorius CA, Groshong SD, Miller LA, Powell RL, Tung L, Takimoto GS, Horwitz KB (1994) New T47D breast cancer cell lines for the independent study of progesterone B- and Areceptors: only antiprogestin-occupied B-receptors are switched to transcriptional agonists by cAMP. Cancer Res 54:38683877

19. Haslam SZ, Drolet A, Smith K, Tan M, Aupperlee M (2008) Progestinregulated luminal cell and myoepithelial cell-specific responses in mammary organoid culture. Endocrinology 149:2098-20107

20. Mote PA, Johnston JF, Manninen T, Tuohimaa P, Clarke CL (2001) Detection of progesterone receptor forms A and B by immunohistochemical analysis. J Clin Pathol 54:624-630

21. Kariagina A, Aupperlee MD, Haslam SZ (2007) Progesterone receptor isoforms and proliferation in the rat mammary gland during development. Endocrinology 148:2723-2736

22. Chen H, Kovar J, Sissons S, Cox K, Matter W, Chadwell F, Luan P, Vlahos CJ, Schutz-Geschwender A, Olive DM (2005) A cell-based immunocytochemical assay for monitoring kinase signaling pathways and drug efficacy. Anal Biochem 338:136142

23. Kariagina A, Romanenko D, Ren SG, Chesnokova V (2004) Hypothalamic-pituitary cytokine network. Endocrinology 145:104 112

24. Kariagina A, Zonis S, Afkhami M, Romanenko D, Chesnokova V (2005) Leukemia inhibitory factor regulates glucocorticoid receptor expression in the hypothalamic-pituitary-adrenal axis. Am J Physiol Endocrinol Metab 289:E857-863

25. Ciarloni L, Mallepell S, Brisken C (2007) Amphiregulin is an essential mediator of estrogen receptor alpha function in mammary gland development. Proc Natl Acad Sci USA 104:5455-5460

26. Sternlicht MD, Sunnarborg SW (2008) The ADAM17-amphiregulinEGFR axis in mammary development and cancer. J Mammary Gland Biol Neoplasia 13:181-194 
27. Kim NS, Kim HJ, Koo BK, Kwon MC, Kim YW, Cho Y, Yokota Y, Penninger JM, Kong YY (2006) Receptor activator of NFkappaB ligand regulates the proliferation of mammary epithelial cells via Id2. Mol Cell Biol 26:1002-1013

28. Turashvili G, Bouchal J, Burkadze G, Kolar Z (2006) Wnt signaling pathway in mammary gland development and carcinogenesis. Pathobiology 73:213-223

29. Brisken C, Heineman A, Chavarria T, Elenbaas B, Tan J, Dey SK, McMahon JA, McMahon AP, Weinberg RA (2000) Essential function of Wnt-4 in mammary gland development downstream of progesterone signaling. Genes Dev 14:650-654

30. Cao Y, Karin M (2003) NF-kappaB in mammary gland development and breast cancer. J Mammary Gland Biol Neoplasia 8:215223

31. Rowlands TM, Pechenkina IV, Hatsell S, Cowin P (2004) Betacatenin and cyclin D1: connecting development to breast cancer. Cell Cycle 3:145-148

32. Eckstein N, Servan K, Girard L, Cai D, von Jonquieres G, Jaehde U, Kassack MU, Gazdar AF, Minna JD, Royer HD (2008) Epidermal growth factor receptor pathway analysis identifies amphiregulin as a key factor for cisplatin resistance of human breast cancer cells. J Biol Chem 283:739-750

33. Cui X, Kim HJ, Kuiatse I, Kim H, Brown PH, Lee AV (2006) Epidermal growth factor induces insulin receptor substrate-2 in breast cancer cells via c-Jun $\mathrm{NH}(2)$-terminal kinase/activator protein-1 signaling to regulate cell migration. Cancer Res 66:5304-5313

34. Lange CA, Shen T, Horwitz KB (2000) Phosphorylation of human progesterone receptors at serine-294 by mitogen-activated protein kinase signals their degradation by the $26 \mathrm{~S}$ proteasome. Proc Natl Acad Sci USA 97:1032-1037

35. Pei RJ, Sato M, Yuri T, Danbara N, Nikaido Y, Tsubura A (2003) Effect of prenatal and prepubertal genistein exposure on $\mathrm{N}$ methyl-N-nitrosourea-induced mammary tumorigenesis in female Sprague-Dawley rats. In Vivo 17:349-357

36. Mote PA, Bartow S, Tran N, Clarke CL (2002) Loss of co-ordinate expression of progesterone receptors $\mathrm{A}$ and $\mathrm{B}$ is an early event in breast carcinogenesis. Breast Cancer Res Treat 72:163-172

37. Aupperlee MD, Smith KT, Kariagina A, Haslam SZ (2005) Progesterone receptor isoforms $\mathrm{A}$ and $\mathrm{B}$ : temporal and spatial differences in expression during murine mammary gland development. Endocrinology 146:3577-3588

38. Gallo D, Zannoni GF, Martinelli E, Ferlini C, Fabrizi M, Riva A, Morazzoni P, Bombardelli E, Scambia G (2006) Estradiol and phytoestrogens differently influence the rodent postmenopausal mammary gland. Menopause 13:72-79

39. Hofseth LJ, Raafat AM, Osuch JR, Pathak DR, Slomski CA, Haslam SZ (1999) Hormone replacement therapy with estrogen or estrogen plus medroxyprogesterone acetate is associated with increased epithelial proliferation in the normal postmenopausal breast. J Clin Endocrinol Metab 84:4559-4565

40. Clarke RB (2003) Steroid receptors and proliferation in the human breast. Steroids 68:789-794

41. Russo J, Ao X, Grill C, Russo IH (1999) Pattern of distribution of cells positive for estrogen receptor alpha and progesterone receptor in relation to proliferating cells in the mammary gland. Breast Cancer Res Treat 53:217-227

42. Britton DJ, Hutcheson IR, Knowlden JM, Barrow D, Giles M, McClelland RA, Gee JM, Nicholson RI (2006) Bidirectional cross talk between ERalpha and EGFR signalling pathways regulates tamoxifen-resistant growth. Breast Cancer Res Treat 96:131-146

43. Wilson CL, Sims AH, Howell A, Miller CJ, Clarke RB (2006) Effects of oestrogen on gene expression in epithelium and stroma of normal human breast tissue. Endocr Relat Cancer 13:617-628
44. Matsumoto K, Fukuda S, Nakamura Y, Saito H (2009) Amphiregulin production by human eosinophils. Int Arch Allergy Immunol 149(Suppl 1):39-44

45. Brunelli E, Pinton G, Chianale F, Graziani A, Appendino G, Moro L (2009) 8-Prenylnaringenin inhibits epidermal growth factorinduced MCF-7 breast cancer cell proliferation by targeting phosphatidylinositol-3-OH kinase activity. J Steroid Biochem Mol Biol 113:163-170

46. Cicenas J (2008) The potential role of Akt phosphorylation in human cancers. Int J Biol Markers 23:1-9

47. Shaulian E, Karin M (2001) AP-1 in cell proliferation and survival. Oncogene 20:2390-2400

48. Shen Q, Zhang Y, Uray IP, Hill JL, Kim HT, Lu C, Young MR, Gunther EJ, Hilsenbeck SG, Chodosh LA, Colburn NH, Brown PH (2006) The AP-1 transcription factor regulates postnatal mammary gland development. Dev Biol 295:589-603

49. Richer JK, Jacobsen BM, Manning NG, Abel MG, Wolf DM, Horwitz KB (2002) Differential gene regulation by the two progesterone receptor isoforms in human breast cancer cells. $\mathrm{J}$ Biol Chem 277:5209-5218

50. Lange CA, Richer JK, Horwitz KB (1999) Hypothesis: progesterone primes breast cancer cells for cross-talk with proliferative or antiproliferative signals. Mol Endocrinol 13:829-836

51. Bamberger AM, Milde-Langosch K, Schulte HM, Loning $\mathrm{T}$ (2000) Progesterone receptor isoforms, PR-B and PR-A, in breast cancer: correlations with clinicopathologic tumor parameters and expression of AP-1 factors. Horm Res 54:32-37

52. McGowan EM, Clarke CL (1999) Effect of overexpression of progesterone receptor $\mathrm{A}$ on endogenous progestin-sensitive endpoints in breast cancer cells. Mol Endocrinol 13:1657-1671

53. Shen T, Horwitz KB, Lange CA (2001) Transcriptional hyperactivity of human progesterone receptors is coupled to their liganddependent down-regulation by mitogen-activated protein kinasedependent phosphorylation of serine 294. Mol Cell Biol 21:61226131

54. Lubet RA, Szabo E, Christov K, Bode AM, Ericson ME, Steele VE, Juliana MM, Grubbs CJ (2008) Effects of gefitinib (Iressa) on mammary cancers: preventive studies with varied dosages, combinations with vorozole or targretin, and biomarker changes. Mol Cancer Ther 7:972-979

55. Ciardiello F, Troiani T, Caputo F, De Laurentiis M, Tortora G, Palmieri G, De Vita F, Diadema MR, Orditura M, Colantuoni G, Gridelli C, Catalano G, De Placido S, Bianco AR (2006) Phase II study of gefitinib in combination with docetaxel as first-line therapy in metastatic breast cancer. Br J Cancer 94:1604-1609

56. Chlebowski RT, Anderson GL, Gass M, Lane DS, Aragaki AK, Kuller LH, Manson JE, Stefanick ML, Ockene J, Sarto GE, Johnson KC, Wactawski-Wende J, Ravdin PM, Schenken R, Hendrix SL, Rajkovic A, Rohan TE, Yasmeen S, Prentice RL (2010) Estrogen plus progestin and breast cancer incidence and mortality in postmenopausal women. JAMA 304:1684-1692

57. Schramek D, Leibbrandt A, Sigl V, Kenner L, Pospisilik JA, Lee HJ, Hanada R, Joshi PA, Aliprantis A, Glimcher L, Pasparakis M, Khokha R, Ormandy CJ, Widschwendter M, Schett G, Penninger JM (2010) Osteoclast differentiation factor RANKL controls development of progestin-driven mammary cancer. Nature 468:98-102

58. Gonzalez-Suarez E, Jacob AP, Jones J, Miller R, Roudier-Meyer MP, Erwert R, Pinkas J, Branstetter D, Dougall WC (2010) RANK ligand mediates progestin-induced mammary epithelial proliferation and carcinogenesis. Nature 468:103-107

59. Aupperlee MD, Drolet AA, Durairaj S, Wang W, Schwartz RC, Haslam SZ (2009) Strain-specific differences in the mechanisms of progesterone regulation of murine mammary gland development. Endocrinology 150:1485-1494 